\title{
Critical Parameters for Particle-Based Pulmonary Delivery of Chemotherapeutics
}

\author{
Ali Dabbagh, PhD, Noor Hayaty Abu Kasim, PhD, Chai Hong Yeong, PhD,2 \\ Tin Wui Wong, $\mathrm{PhD}^{3}$, and Noorsaadah Abdul Rahman, $\mathrm{PhD}^{4,5}$
}

\begin{abstract}
Targeted delivery of chemotherapeutics through the respiratory system is a potential approach to improve drug accumulation in the lung tumor, while decreasing their negative side effects. However, elimination by the pulmonary clearance mechanisms, including the mucociliary transport system, and ingestion by the alveolar macrophages, rapid absorption into the blood, enzymatic degradation, and low control over the deposition rate and location remain the main complications for achieving an effective pulmonary drug delivery. Therefore, particlebased delivery systems have emerged to minimize pulmonary clearance mechanisms, enhance drug therapeutic efficacy, and control the release behavior. A successful implementation of a particle-based delivery system requires understanding the influential parameters in terms of drug carrier, inhalation technology, and health status of the patient's respiratory system. This review aims at investigating the parameters that significantly drive the clinical outcomes of various particle-based pulmonary delivery systems. This should aid clinicians in appropriate selection of a delivery system according to their clinical setting. It will also guide researchers in addressing the remaining challenges that need to be overcome to enhance the efficiency of current pulmonary delivery systems for aerosols.
\end{abstract}

Keywords: chemotherapeutics, clearance, particles, pulmonary drug delivery systems

\section{Introduction}

I N SPITE OF THE INHERENT ADVANTAGES of the pulmonary route for administration of chemotherapeutics, the presence of bio-barriers such as mucus, ciliated cells, and resident macrophages in the respiratory tract could considerably hamper the targeting, diffusion, and adsorption of the inhaled drugs. ${ }^{(1)}$ The negative effect of chemotherapeutics on the lung parenchyma is another obstacle for their direct administration into the lungs. ${ }^{(2)}$ To overcome these challenges, particle-based pulmonary delivery systems (PPDS) have been recently employed to achieve localized supply of chemotherapeutics, enhance drug bioavailability, avoid various pulmonary clearance procedures, and minimize the metabolic degradation. For an effective drug targeting, several parameters, including the physicochemical characteristics of the chemotherapeutics, carrier properties, type of the inhalation device, as well as the tumor type and location, must be considered.
This work is an attempt to review different carrier-, device-, and patient-related factors that have been reported to significantly affect the PPDS success in the clinical setting. Therefore, it could aid researchers in appropriate selection, design, and customization of a PPDS according to their specific treatment procedure. Moreover, this review highlights a number of research gaps that could be addressed in future to increase the PPDS efficacy for treatment of various lung tumors.

\section{Particle-Based Parameters}

A desirable inhalation performance requires optimization of various particle properties. The particle composition, size, morphology, surface characteristics, aqueous solubility, dispersion/agglomeration state, fluid $\mathrm{pH}$, targeting moieties, and the chemotherapeutic type are the most studied physicochemical parameters for optimization of the PPDS performance.

\footnotetext{
${ }^{1}$ Wellness Research Cluster, Institute of Research Management and Services, University of Malaya, Kuala Lumpur, Malaysia.

${ }^{2}$ Department of Biomedical Imaging, Faculty of Medicine, University of Malaya, Kuala Lumpur, Malaysia.

${ }^{3}$ Department of Pharmaceutics and Pharmaceutical Biotechnology, Faculty of Pharmacy, Universiti Teknologi MARA, Puncak Alam, Malaysia.

${ }^{4}$ Department of Chemistry, Faculty of Science, University of Malaya, Kuala Lumpur, Malaysia.

${ }^{5}$ Drug Design and Development Research Group (DDDRG), University of Malaya, Kuala Lumpur, Malaysia.
} 
A number of other influential factors such as particle density, molecular weight, osmolality, ionic strength, viscosity, penetrability through the airway mucus, ability to escape from the mucociliary clearance and phagocytosis, rate of entrapment and inactivation by the bacterial biofilms, and tendency to interact with host proteins are also considered significant in PPDS design. However, to the best of our knowledge, limited studies have specifically investigated the influence of these parameters on the PPDS efficacy and thus, these parameters were excluded in this review.

\section{Material composition}

Similar to other drug delivery systems, sufficient physiochemical stability in the biological medium, bioavailability at the target tumor, and biodegradability after drug release are the general material characteristics that must be considered in the PPDS design. Different carriers, including lipid-, polymer-, and gelatin-based particles, have shown potential to present these general properties and are, thus, widely employed in PPDS design. A number of metallic (e.g., iron oxide and gold) and ceramic (e.g., mesoporous silica) compounds have also been used in PPDS development. However, translation of these carriers into the clinical setting is challenging due to the remaining concerns on their low biodegradability and potential pulmonary toxicological effects.

Lipid-based carriers. The lipid-based carriers employed in PPDS design could be generally categorized to liposomes, solid lipid nanoparticles (SLNs), and nano-sized lipid carriers (NLCs). Liposomal formulations with compositions similar to lung surfactants could serve as potential carriers for pulmonary delivery of therapeutics, owing to their low local irritation to the lung parenchyma, high biodegradability, sustained release behavior, ${ }^{(3-10)}$ controllable surface charge ${ }^{(11-14)}$ as well as capability of encapsulating hydrophilic, ${ }^{(15-17)}$ amphiphilic, ${ }^{(15)}$ or hydrophobic ${ }^{(15,18-21)}$ compounds. Liposomes could also be produced in both dry powder ${ }^{(22)}$ and liquid suspension ${ }^{(23-25)}$ forms based on the pulmonary delivery setup.

In general, the liposomal aerosols could significantly extend the drug retention half-life, improve their intracellular diffusion and bioavailability, enhance the tissue tolerance against high drug dosages, and minimize the pulmonary clearance via protecting the chemotherapeutics from enzymatic degradation. ${ }^{(25-27)}$ For instance, the area under the curve (AUC), half-life, and mean residence time of gemcitabine encapsulated in inhalable liposomal dry powders were, respectively, found to be $8.3,5.3$, and 5.7 times higher than that of drug solution. ${ }^{(10)}$ Inhalation of doxorubicin-encapsulated liposomes induced considerably higher cell death at the target tissue in the mice lungs and substantially decreased negative side effects in the nontarget organs such as kidneys, liver, and spleen in contrast to free doxorubicin or doxorubicin-encapsulated liposomes administrated intravenously. ${ }^{(28)}$

SLNs and NLCs are other submicron-sized lipid-based biocarriers, composed of solid hydrophobic cores entangled by monolayer phospholipid shells. ${ }^{(29-34)}$ The SLNs and NLCs have been employed for pulmonary delivery of phenethyl isothiocyanate, ${ }^{(35)}$ paclitaxel, ${ }^{(29)}$ and celecoxib, ${ }^{(36)}$ showing high potential for nebulization to lower lung regions when appropriate aerodynamic properties are achieved. After inhalation, SLNs could be uptaken into the lymphatic nodes, and rapidly deposited in periaortic, axillar, and inguinal lymph nodes. ${ }^{\text {(37) }}$

The therapeutic activity, transferred drug dosage, deposition/release rates, and cytotoxicity of the lipid-based carriers in the lung parenchyma depend on the lipid composition (e.g., phospholipid type and content, rigidity, cholesterol content, saturated-unsaturated lipid ratio, and other additives), $(38,39)$ size, ${ }^{(40-43)}$ surface properties, ${ }^{(43-45)}$ drug characteristics, ${ }^{(38,41,43)}$ drug-to-lipid ratio, ${ }^{(39-41,43)}$ process parameters, ${ }^{(39,41)}$ and delivery technique. ${ }^{(27,46,47)}$ Hence, alteration of the lipid composition and fabrication protocol could result in highly customized physicochemical properties that substantially affect the PPDS efficacy in the target site.

Polymer-based carriers. Polymeric carriers are mostly fabricated from synthetic or natural biodegradable compounds, including polylactic-co-glycolic acid (PLGA), ${ }^{(4-51)}$ polyethylene glycol (PEG), ${ }^{(52)}$ and their conjugates with other biopolymers such as polyesters, ${ }^{(53)}$ chitosan, ${ }^{(54-57)}$ and dextran, ${ }^{(58)}$ which offer potential advantages over lipid-based carriers in terms of physical and chemical stability, drug encapsulation capability, sustained drug release, and prolonged pharmacological activity of their cargos. In particular, deep deposition in the lower lung regions, low aggregation tendency, and high mechanical stability under the shear forces make polymeric particles suitable for pulmonary delivery of chemotherapeutics. Different chemotherapeutics such as doxorubicin, ${ }^{(49,51)}$ paclitaxel, ${ }^{(51)}$ cisplatin, ${ }^{(57)}$ and 5-fluorouracil ${ }^{(59)}$ have been encapsulated within the polymeric particles.

A variety of carrier parameters, including concentration, morphology, hydrophilicity, molecular weight, and porosity of the polymeric carriers, as well as the environmental factors such as temperature, $\mathrm{pH}$, solvent polarity, moisture content, and physicomechanical stresses show crucial effects on the efficacy of pulmonary delivery by polymeric carriers.

Polymeric micellar structures have also been broadly utilized in PPDS development due to their structural similarity to biological compounds such as lipoproteins and viruses. The micellar structures generally exhibit high loading capacity and biocompatibility, which reflect their high potential for pulmonary administration. ${ }^{(60,61)}$ Due to their hydrophilic shell, micelles could evade clearance by the alveolar macrophages, diffuse through the mucus layer, and penetrate into the epithelial cells. In particular, the hydrophobic core allows encapsulation of the hydrophobic chemotherapeutics such as docetaxel, ${ }^{(62)}$ which could further be easily uptaken by the tumor cells. ${ }^{(28)}$

Polymeric compounds with dendrimer structure such as PEGylated polylysine have also been used in pulmonary delivery of chemotherapeutics. ${ }^{(63)}$ Intratracheal instillation of the dendrimer-conjugated doxorubicin into the rat lungs resulted in around a 15\% dose retention in the lungs after a week of administration. A comparison between the efficacy of administration route demonstrated that the pulmonary delivery of dendrimer-conjugated doxorubicin resulted in a higher than $95 \%$ reduction in the lung tumor volume after 2 weeks whereas only $30 \%-50 \%$ reduction was observed when the drug was received intravenously. ${ }^{(63)}$

Gelatin-based carriers. Gelatin-based nanoparticles (GNP) have been employed in pulmonary delivery of doxorubicin ${ }^{(64)}$ and cisplatin. ${ }^{(65,66)}$ Similar to other nanotechnology approaches, GNP demonstrated enhanced anti-cancer activity, 
sustained drug release, and low toxicity. The IC50 was as low as $1.2 \mu \mathrm{g} / \mathrm{mL}$ for cisplatin-loaded GNP compared with free cisplatin $(2.54 \mu \mathrm{g} / \mathrm{mL}){ }^{(67)}$ In addition, cisplatin accumulation in the lung tumor after inhalation by mice was much higher for the particle-based formulation compared with the free cisplatin solution. ${ }^{(60)}$

Comparative investigation of different material compositions. Comparative studies regarding the efficacy of various carrier compounds for pulmonary drug delivery are scarce. However, in an attempt to select a carrier that serves as the optimal choice for pulmonary delivery of anticancer drugs, different nanocarriers including liposomes, PEG, distearoyl phosphoethanol amine-amino PEG micelles (DSPE-PEG), mesoporous silicon nanoparticles (MSNs), and polypropyleneimine dendrimer conjugated with siRNA were analyzed and compared in terms of their degrees of lung accumulation as well as deposition profiles in different nontarget tissues (Fig. 1). ${ }^{(28)}$

It was found that when the carriers were inhaled by mice, the accumulation and retention ratios in the lungs were more independent of the carrier material in contrast to intravenous administration. However, the accumulation degrees and retention periods of liposomes, micelles, and PEG in the lungs were relatively higher compared with those of MSNs and dendrimers. ${ }^{(28)}$ Therefore, it can be concluded that PPDS development using liposome- or polymer-based particles could result in relatively higher efficacies in contrast to other carrier compounds.

\section{Particle size}

The effect of mass median aerodynamic diameter (MMAD) on the distribution pattern and deposition site of the inhaled particles has been investigated in numerous studies. ${ }^{(68-72)}$ In general, the particles with different MMAD values are deposited by impaction, interception, sedimentation, or diffusion mechanisms. ${ }^{(73)}$

In addition, the MMAD values could significantly affect the activity of various lung clearance mechanisms that intensify during lung diseases. These mechanisms are considered as the major obstacle that the inhaled particles encounter, leading to rapid clearance from the lungs before reaching the target site. ${ }^{(74)}$ The inhaled particles are mostly cleared by mucociliary clearance or alveolar macrophages, depending on their deposition region. For instance, the particles with MMADs larger than $6000 \mathrm{~nm}$ that mostly accumulate at the upper airways are eliminated by mucociliary clearance in the epithelia tissue. When the foreign particles are trapped in mucus, cilia beat in a coordinated direction (pharynx) to remove the freight by either coughing or swallowing. ${ }^{(74)}$ In general, the particles with MMADs of 1000 to $5000 \mathrm{~nm}$ are shown to evade the mucociliary clearance and accumulate in the narrower airways. ${ }^{(75)}$

Clearance by the alveolar macrophages is the secondary challenge that the particles encounter during their travel in the pulmonary system. ${ }^{(74)}$ Although the particles with MMADs of $1000-5000 \mathrm{~nm}$ are shown to escape the mucociliary clearance, the MMAD range of $2000-3000 \mathrm{~nm}$ is prone to a faster recognition and elimination by the resident alveolar macrophages. ${ }^{(76)}$

In recent years, an increasing interest has been dedicated to the particles in nano-sized range due to their easier incorporation into the "respirable ratio," leading to enhanced uniformity of drug distribution within the alveoli. (77) Moreover, the nano-sized carriers are able to deposit at the lining fluid and evade the lung clearance mechanisms. ${ }^{78,79)}$ However, application of nano-sized carriers in pulmonary

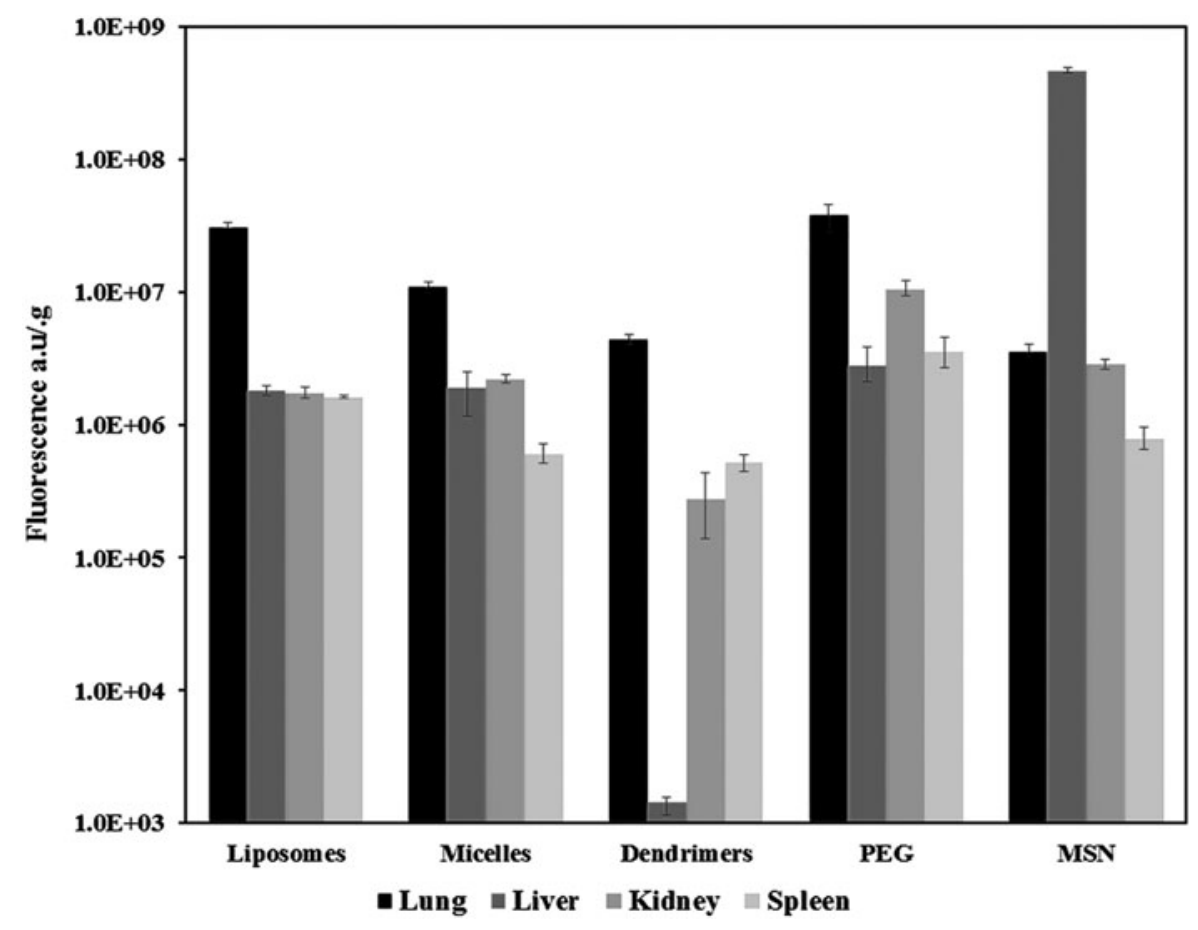

FIG. 1. Comparative investigation of accumulation of different carrier materials in various tissues. ${ }^{(2)}$ The particle size of liposome formulation was $600 \mathrm{~nm}$, and the molecular weight of PEG particles was $2 \mathrm{kDa}$. PEG, polyethylene glycol. 
drug delivery remains challenging due to their high aggregation tendency and low weight, which results in their rapid exhalation.

Due to this limitation, the drug-carrying nanoparticles require secondary carriers with appropriate MMADs to obtain the synergistic effect of both micron- and nano-sized carriers. ${ }^{(80)}$ For instance, SLN nanoparticles encapsulated in mannitol microspheres $^{(81)}$ as well as chitosan-encapsulating mannitol ${ }^{(56,82)}$ and sodium alginate ${ }^{(83)}$ have shown desirable aerodynamic characteristics, high encapsulation capacity, and high biocompatibility/biodegradability, which indicate their potency for application as pulmonary drug delivery systems. These carriers could also be selected from the stimuli-responsive compounds that swell in the respiratory tract due to moisture absorption, resulting in preferred deposition in the deep lung and minimized elimination by the lung clearance mechanisms. ${ }^{(84)}$

In order to avoid both clearance mechanisms, while simultaneously obtaining high fractions of respirable delivery and sufficient chemotherapeutic dosages in the lower respiratory tract, it is suggested to encapsulate nano-sized carriers with particle sizes of less than $200 \mathrm{~nm}$ into the secondary carriers with MMADs ranging from 3000 to $5000 \mathrm{~nm}$.

\section{Carrier shape}

In addition to particle size, the particle shape also influences the PPDS efficacy via modulation of the alveolar macrophage clearance. Investigation of the geometrically opsonized and nonopsonized polystyrene particles with different morphological conformations, including oblate ellipsoids, elliptical disks, rectangular disks, spheres, and worm-like shape, indicated that the orientation and shape of these materials substantially affect their phagocytosis clearance hours. ${ }^{(85,86)}$ An orientation bias was observed in the macrophage function, where the elliptical disks where engulfed in less than 6 minutes due to the attachment of macrophages to their major axes. The spherical particles were also immediately cleared regardless of the macrophage attachment point. In contrast, macrophage attachment to the flat surfaces or minor axes of the rectangular disks, elliptical disks, and oblate ellipsoids could not clear these particles even in 2 hours. ${ }^{(85)}$

Inhalation of the particles with a worm-like shape also resulted in significantly less phagocytosis clearance in contrast to spherical shape mainly because of their low curvature region. The worm-like carriers were engulfed only when the macrophages attached to the main axes possessing high curvatures, whereas the longitudinal attachment of macrophages resulted in minimized clearance because of their low curvature in this direction. ${ }^{(86)}$

\section{Surface properties}

The particles' surface properties are known to significantly influence their bioavailability in the tumor cells. In particular, the surface properties determine the hydrophilicity degree, surface charge, biocompatibility or cytotoxicity, and stealth characteristics. In general, the particle distribution in the extracellular matrix as well as their penetration between and into the cells significantly rely on their degree of hydrophilicity. In contrast, lyophilic particles could more readily enter the cells due to their higher diffusivity in the lipid membranes.

The cell uptake is also controlled by the particles' surface charge, where the positively charged particles could penetrate easily into tumor cells due to their higher binding activity with tumor cells. On top of that, the particles' stability in the suspension is greatly improved when the zeta potential values are above $\pm 30 \mathrm{Mv} .^{(87,88)}$ Investigation of the zeta potential values of various carrier compounds indicated approximately neutral charges for most of the common inhalation materials. Although the liposomes and micelles exhibit slight negative charges, however these materials are still classified as "neutral" carriers in the drug delivery application. ${ }^{(28)}$

The surface properties also substantially influence the clearance mechanism in the pulmonary system, where adhesion interactions between the particles and mucus usually occur via electrostatic, hydrophobic, and hydrogen bonding. ${ }^{(89)}$ For instance, in the patients who simultaneously suffer from cystic fibrosis, over-production of a highly viscous mucus drastically limits the drug bioavailability in the tumor site. More than a 10fold increase in mucus production is also observed in chronic bronchitis patients compared with healthy subjects.

It is, therefore, necessary to manipulate the physicochemical properties of the carriers such as surface charge or hydrophobicity to provide "stealth characteristics" for minimization of absorption, degradation, entrapment in the mucus, and thus increasing the penetration depth and prolonging half-life of the inhaled drugs across the mucus layers. The stealth behavior is generally obtained by conjugation of a lipid ${ }^{(90)}$ or formation of a hydration layer such as hyaluronic acid (a muco-adhesive polysaccharide available in the pulmonary system) on the particles' surface to suppress the immune recognition, phagocytosis, and biofouling. ${ }^{(91,92)}$ The hydrophilic polymers such as PEG, polyethylene oxide, and poloxamine have also been widely used as coating layers on various carriers such as liposomes and SLNs. ${ }^{(44,92-94)}$

\section{Secondary carriers}

As previously discussed, nano-sized drug carriers require to be encapsulated in micron-sized "secondary carriers" to decrease their exhalation rate. Carbohydrate formulations such as glucose, mannitol (polyol), maltitol, sorbitol, xylitol, and lactose (a-lactose monohydrate) are the most widely used secondary carriers that have shown great potency to enhance stability, dispersability, and flowability of the encapsulated therapeutics. However, a number of studies have shown that mannitol is the optimal secondary carrier for enhancing dispersability of the encapsulated nanoparticles incorporated in dry powder inhaler (DPI) formulations. ${ }^{(95)}$ On the contrary, the intracellular uptake of polylysine encapsulated into lactose has been found to be higher than other carbohydrates. ${ }^{(96)}$

The drug dispersability and delivery efficacy could further be enhanced by addition of a ternary component such as L-leucine to the lactose formulation to occupy the sites with high bonding energies and, thus, reduce the carrier-drug interaction. ${ }^{(97)}$ Moreover, addition of the coarser lactose particles to the initial fine lactose particles with MMADs of $\sim 5000 \mathrm{~nm}$ could increase their fine particle fraction and disaggregation. ${ }^{(98)}$

\section{Chemotherapeutic agent}

Combination chemotherapy using platinum-based drugs such as cisplatin is still the backbone regimen for treatment of various lung cancers. Cisplatin contains a central platinum atom surrounded by two chloride and two ammonia molecules in the cis position as the leaving and carrier 
<smiles>N[Pb](N)Cl</smiles>

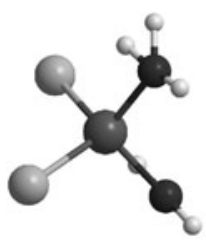

Cisplatin
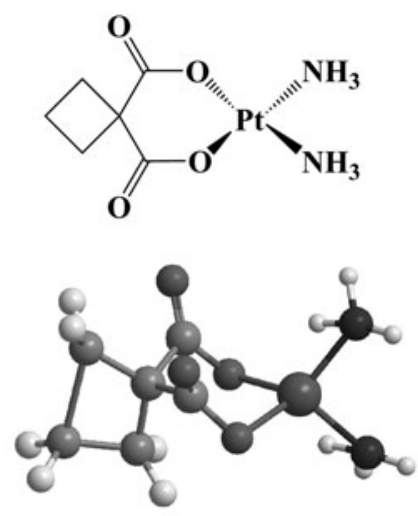

Carboplatin<smiles>O=C1O[Te]2(N[C@H]3CCCC[C@H]3N2)OC1=O</smiles>

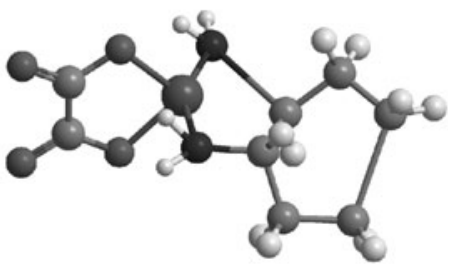

Oxaliplatin

FIG. 2. Chemical structures of the platinum-based chemotherapeutics used in lung cancer treatment.

ligands, respectively (Fig. 2). ${ }^{(99)}$ Cisplatin exerts its cytotoxic effect via formation of chemical bonds with genomic DNA and inhibition of the cell replication and transcription. ${ }^{(99,100)}$ When crossing the cell membrane, cisplatin undergoes a nonenzymatic conversion to reactive derivatives through displacement of its chloride atoms and further binds to the DNA bases through the N7 atom (preferably guanine). ${ }^{(99,100)}$

The main limiting parameters in application of cisplatin are a relatively low aqueous solubility, high toxicity, and a short halflife. ${ }^{(101)}$ High reactivity of the chloride ligand leads to formation of irreversible conjugates with proteins before reaching the cell nuclei and rapid excretion from the body. Therefore, a number of cisplatin analogues such as carboplatin, oxaliplatin, nedaplatin, heptaplatin, and lobaplatin have been developed as the secondand third-generation platinum-based chemotherapeutics to achieve superior aqueous solubility, higher antitumor activity with lower adverse effects (AEs), and longer half-lives. ${ }^{(102)}$

In particular, carboplatin and oxaliplatin have shown promising efficacies comparable to cisplatin in treatment of various lung tumors. Carboplatin is produced by replacement of chloride with bidentate dicarboxylate, resulting in higher aqueous solubility but lower reactivity and slower DNA-binding kinetics. In contrast, oxaliplatin contains cyclohexyldiamine carrier groups for enhanced antitumor activity as well as oxalato bidentate leaving ligands to obtain higher aqueous solubility and slightly lower reactivity (Fig. 2). Cisplatin is the most-highly protein bound (higher than $90 \%)$, followed by oxaliplatin $(\sim 85 \%)$, and carboplatin $(24 \%-50 \%)$. The diminished reactivity limits proteindrug complexes, which further results in a higher half-life due to a slower excretion from the body (Table 1). ${ }^{(99,100)}$

The possible AEs of platinum-based chemotherapeutics have been investigated in a number of clinical studies. Overall, cisplatin exerts more severe nephrotoxicity, neurotoxicity, ototoxicity, chronic vascular toxicity, as well as gastrointestinal toxicities such as nausea, vomiting, and diarrhea in contrast to carboplatin and oxaliplatin, ${ }^{(103,104)}$ probably due to its highly reactive leaving groups. ${ }^{(100)}$ In contrast, dose-limiting myelotoxicity, particularly thrombocytopenia, ${ }^{(104)}$ as well as relevant hematologic toxicity profile when used in equipotent dosages $^{(104)}$ represent the most prominent AE of carboplatin. On the other hand, sensory peripheral neuropathy has been reported as the dose-limiting toxicity (DLT) of oxaliplatin therapy. ${ }^{(103)}$ However, a meta-analysis study indicated similar grades 3 and 4 sensory neuropathies and thrombocytopenia in oxaliplatin and carboplatin/cisplatin therapies and less thrombocytopenia, neutropenia, and leukocytopenia in oxaliplatin treatments. ${ }^{(104)}$

Currently, platinum-based regimens combined with other doublets are prescribed as the gold standard for chemotherapeutic treatment of lung cancer. ${ }^{(104)}$ The combination regimens initially consisted of cisplatin plus vinblastine, vindesine, etoposide, mitomycin, ifosfamide, fluorouracil, or doxorubicin (second-generation regimens); whereas more recently, modern agents such as vinorelbine, paclitaxel, docetaxel, gemcitabine, camptothecin, azacitidine, or pemetrexed are widely employed (the third-generation regimens) as monotherapy or combined with platinum-based compounds (Table 1). ${ }^{(105)}$

A number of randomized clinical trials have investigated the efficacy of platinum-based doublets in treatment of lung cancer. ${ }^{(106-108)}$ Recently, a meta-analysis on the efficacy of cisplatin, carboplatin, and oxaliplatin indicated that the oxaliplatinbased regimens combined with third-generation agents such as vinorelbine, paclitaxel, docetaxel, gemcitabine, and pemetrexed could provide comparable clinical efficacy to those of cisplatin and carboplatin with lower toxicity, as well as sufficient safety for outpatient setting without necessity of specific hydration treatments. ${ }^{(104)}$ Therefore, oxaliplatin combined with thirdgeneration chemotherapeutics could be used as an efficient intervention, especially for elderly patients or those who are unable to tolerate the toxicity levels of conventional platinum-based regimens. ${ }^{(104)}$ The most common combination therapies used in PPDS will be highlighted in the following sections.

\section{Targeting ligands}

Active targeting using surface-bound ligands specific to the receptors overexpressed on the lung cancer cells is a potential approach to obtain improved drug accumulation in the tumor. More importantly, this strategy could allow drug internalization via the receptor-mediated endocytosis and overcome the drug resistance through bypassing the membrane efflux pumps. ${ }^{(109)}$

All the receptors including epidermal growth factor receptor (EGFR or HER-1), echinoderm microtubule-associated protein- 
Table 1. Physicochemical Properties of Various Chemotherapeutics Used in Inhalational Delivery (WWW.DRUGBank.Ca)

\begin{tabular}{|c|c|c|c|c|c|}
\hline & \multirow{2}{*}{$\begin{array}{l}\text { Water solubility } \\
\quad(\mathrm{mg} / \mathrm{mL})\end{array}$} & \multirow[b]{2}{*}{ Half-life(min) } & \multirow[b]{2}{*}{$\log \mathrm{p}$} & \multicolumn{2}{|c|}{$p K a$} \\
\hline & & & & Strongest acidic & Strongest basic \\
\hline Cisplatin & 2.530 & $20-30^{\mathrm{a}}$ & $-2.19-0.04$ & - & 5.06 \\
\hline Carboplatin & 10.00 & $150-350$ & 1.06 & - & -6.60 \\
\hline Oxaliplatin & 27.50 & Triphasic $^{\mathrm{b}}$ & -0.47 & & - \\
\hline Vinblastine & 0.0169 & Triphasic $^{c}$ & $4.18-4.22$ & 10.87 & 8.86 \\
\hline Vindesine & 0.07 & $\sim 1440$ & $2.79-3.53$ & 11.34 & 8.68 \\
\hline Etoposide & 0.978 & $240-660$ & $0.73-1.16$ & 9.33 & -3.70 \\
\hline Mitomycin & 10.1 & $8-48$ & $-3.00--0.55$ & 6.80 & -0.30 \\
\hline Ifosfamide & 15.0 & $420-900$ & $0.10-0.57$ & 13.24 & 0.12 \\
\hline Fluorouracil & 5.860 & $10-20$ & $-0.66--0.58$ & 7.76 & -8 \\
\hline Doxorubicin & 1.180 & $1200-2880$ & $0.92-1.41$ & 9.53 & 8.94 \\
\hline Vinorelbine & 0.0122 & $1660-2616$ & $4.39-4.65$ & 10.87 & 8.72 \\
\hline Paclitaxel & 0.006 & $\sim 53^{\mathrm{d}}$ & $3.20-3.54$ & 10.36 & -1 \\
\hline Docetaxel & 0.013 & Dose dependent $\mathrm{e}^{\mathrm{e}}$ & $2.59-2.92$ & 10.96 & -3 \\
\hline Gemcitabine & 22.3 & $\begin{array}{l}42-94 \text { (short infusions) } \\
245-638 \text { (long infusions) }\end{array}$ & $-1.50-0.14$ & 11.52 & -1.30 \\
\hline Camptothecin & 0.511 & $\sim 10$ & $1.22-1.91$ & 11.71 & 3.70 \\
\hline Azacitidine & 12.1 & 240 & $-3.10--2.50$ & 12.55 & -0.38 \\
\hline Pemetrexed & 0.0905 & 210 & $-0.25--0.19$ & 3.34 & 7.13 \\
\hline
\end{tabular}

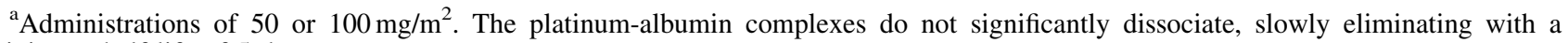
minimum half-life of 5 days.

${ }^{\mathrm{b}}$ Two short half-life distribution phases of $\mathrm{t} 1 / 2 \alpha(\sim 25$ minutes) and $\mathrm{t} 1 / 2 \beta$ ( $\sim 1000$ minutes), followed by a long terminal elimination of $\mathrm{t} 1 / 2 \gamma(\sim 23,500$ minutes $)$.

${ }^{\mathrm{c}} 35,53$, and $\sim 1140$ minutes.

${ }^{\mathrm{d}}$ For a 24 hour infusion of $135 \mathrm{mg} / \mathrm{m}^{2}$ given to ovarian cancer patients.

${ }^{\mathrm{e}}$ At dosages lower than $70 \mathrm{mg} / \mathrm{m}^{2}$, the terminal elimination phase was not detected due to the assay limitations. A triphasic elimination profile was seen at dosages of $70 \mathrm{mg} / \mathrm{m}^{2}$ and higher, with half-lives of 4,36 , and 11.1 hours for the $\alpha, \beta$, and $\gamma$ phases, respectively.

like 4 anaplastic lymphoma kinase receptor (EML4-ALK), erbb2 receptor tyrosine kinase 2 (HER-2), folate receptor $\alpha$, transferrin receptor, epithelial cell adhesion molecule, intercellular adhesion molecule 1, interleukin-4, prostate-specific membrane antigen, as well as K-RAS, MET, RET, ROS-1, and B-RAF proto-oncogenes that are present in the lung tumor cells or those in the tumor cell vasculature such as vascular endothelial growth factor could be targeted by their corresponding ligands bound on the nanocarrier surfaces.

Numerous studies have been carried out to functionalize drug-carrying particles via attachment of monoclonal antibodies, small molecules, peptides, proteins, or aptamers as targeting moieties to different receptors overexpressed in the lung cancer cells (Tables 2 and 3). However, few attempts have been made to conjugate targeting ligands on PPDS to enhance their tumor selectivity and thus, a comparison of the efficacy of these ligands in pulmonary delivery is not currently possible.

In two early studies, luteinizing hormone-releasing hormone was conjugated on the doxorubicin/cisplatin-loaded $\mathrm{MSNs}^{(110)}$ and lipids ${ }^{(5)}$ for inhalation treatment of nonsmall cell lung cancer (NSCLC), resulting in preferential accumulation in the lungs and limited diffusion in the systemic circulation. More recently, the tumor necrosis factor-related apoptosis-inducing ligand (Apo2L/TRAIL) has also been conjugated on the PLGA ${ }^{(11)}$ and lipid ${ }^{(12)}$ carriers to improve drug targeting and internalization via binding to the death receptors 4 and 5 (DR4 and DR5). Conjugation of nanocarriers with different ligands specific to the receptors overexpressed in lung cancer cells could be an interesting area of research to determine the best targeting moiety that results in maximum targeting and internalization of chemotherapeutics.

\section{Device-Based Parameters}

In general, nebulizers are the preferred choice for delivery of chemotherapeutics as small droplets continuously over acceptable periods. ${ }^{(113)}$ These devices could provide a relatively high dosage to the lungs, which makes them suitable for application in emergency cases. ${ }^{(114)}$ Due to a remarkably little specialized inhaled coordination required in contrast to other similar devices, nebulizers are applicable for both children younger than 2 years and elderly patients who are generally unable to control their breathing or receiving mechanical ventilation. ${ }^{(115)}$

DPIs have also been used recently in inhalational delivery of drug carriers such as cisplatin-loaded chitosan. ${ }^{(57)}$ The DPI advantages include high stability, noninvasiveness, sustained release profile, rapid onset of action, propellant freeness, environment friendly, and cost-effectiveness. ${ }^{(116)}$ In addition, the dried powder state seems ideal for the delivery of hydrophobic formulations with low shear tolerances. Compared with nebulizers, DPI is more convenient to use without necessity of storage in cold conditions or reconstitution into solution before inhalation. ${ }^{(76)}$

Nebulizers and DPIs are the most widely used devices for generation of aerosols containing chemotherapeutics. However, a comparative study on the efficacy of different types of nebulizers and DPIs in inhalational delivery of chemotherapeutics has not been carried out so far. Although it may be assumed that the clinical performances of nebulizers and 
Table 2. Various Targeting Moieties Conjugated on Nanocarriers for Lung Cancer Treatment

\begin{tabular}{|c|c|c|c|c|}
\hline Target cells & Marker & Ligand type & Ligand & Carrier \\
\hline \multirow[t]{22}{*}{ Cancer } & \multirow[t]{8}{*}{ EGFR } & Monoclonal antibody & Cetuximab & $\begin{array}{l}\text { Mesoporous silica, }{ }^{(128)} \text { gold/iron, } \\
\text { Gold, }{ }^{(130,131)} \text { Liposome }_{(132)} \text { PLGA, } \\
\text { Chitosan }\end{array}$ \\
\hline & & & Panitumumab & Gold $^{(137)}$ \\
\hline & & \multirow{4}{*}{ Small molecule } & Matuzumab & Iron oxide ${ }^{(138)}$ \\
\hline & & & Erlotinib & PCL/liposome ${ }^{(139)}$ \\
\hline & & & Gefitinib & Gold, ${ }^{(140)}$ Mesoporous silica ${ }^{(128)}$ \\
\hline & & & Afatinib & Gold $^{(141)}$ \\
\hline & & \multirow[t]{2}{*}{ Peptide } & EGF & Lipid, ${ }^{(142)}$ Gelatin $^{(64,67)}$ \\
\hline & & & $\mathrm{EV}$ & Liposome $^{(143)}$ \\
\hline & EML4-ALK & Small molecule & Crizotinib & Micelles ${ }^{(144,145)}$ \\
\hline & K-RAS & Small molecule & Selumetinib & Layer-by-layer NPs ${ }^{(146)}$ \\
\hline & \multirow[t]{2}{*}{ MET } & \multirow[t]{2}{*}{ Small molecule } & Cabozantinib & Micelles \\
\hline & & & Crizotinib & Micelles $(144,145)$ \\
\hline & ROS-1 & Small molecule & Crizotinib & Micelles ${ }^{(144,145)}$ \\
\hline & $\mathrm{FR} \alpha$ & Small molecule & Folic acid & $\begin{array}{l}\text { Iron oxide, }{ }^{(148)} \text { Mesoporous silica, } \\
\text { PEG/PLGA },{ }^{(150)} \text { Chitosan, }{ }^{(151)} \text { Liposome }^{(152)}\end{array}$ \\
\hline & TFR & Glycoprotein & Transferrin & PEG, ${ }^{(153)}$ Lipid/PLGA $^{(154)}$ \\
\hline & IL-4 & Peptide & IL4RPep-1 & Liposome $^{(155)}$ \\
\hline & PSMA & Small molecule & Acupa & PLA/PEG ${ }^{(156)}$ \\
\hline & ICAM-1 & Peptide & cLABL & PLGA $^{(157)}$ \\
\hline & \multirow[t]{2}{*}{ EpCAM } & \multicolumn{2}{|l|}{ Monoclonal antibody } & PEG/PLA ${ }^{(158)}$ \\
\hline & & Aptamers & RNA & PLGA/PEG ${ }^{(159)}$ \\
\hline & LHRHR & Peptide & LHRH & Mesoporous silica, ${ }^{(110)} \operatorname{lipid}^{(5)}$ \\
\hline & DR4, DR5 & Protein & TRAIL & PLGA, ${ }^{(111)}$ Liposome $^{(112)}$ \\
\hline \multirow[t]{2}{*}{ Vasculature } & \multirow[t]{2}{*}{ VEGF } & Small molecule & Endostatin & Gold $^{(160)}$ \\
\hline & & Aptamers & RNA & Liposome, ${ }^{(161)}$ lipid/calcium phosphate ${ }^{(162)}$ \\
\hline
\end{tabular}

EGFR, epidermal growth factor receptor; EpCAM, epithelial cell adhesion molecule; FR $\alpha$, folate receptor $\alpha$; ICAM-1, intercellular adhesion molecule 1; LHRHR, luteinizing hormone-releasing hormone receptor; PSMA, prostate-specific membrane antigen; TFR, transferrin receptor; VEGF, vascular endothelial growth factor; DR, death receptor.

DPIs with other therapeutics ${ }^{(114,117)}$ could be generalized for chemotherapeutics, comparative in vitro, in vivo, and clinical investigation of their performances when specifically used for inhalational delivery of chemotherapeutic-carrying particles could present a more clear conclusion in terms of overall performance, inhalation time, generated particle size, drug stability, delivered dosages to the lung, deposition rate, consistency of the delivered dosage, and drug loss.

\section{Patient-Related Parameters}

Development of new inhalational delivery systems necessitates an understanding of the lung cancer types and presence of other lung diseases that affect the lungs' structure. ${ }^{(114)}$

\section{Cancer type}

Lung cancers are typically classified into small cell lung cancer (SCLC) and NSCLC ${ }^{(118)}$ according to their histology and treatment approaches. The SCLC type, which represents $13 \%-18 \%$ of the total cases, has been traditionally categorized into two clinicopathological stages, including the limited stage (LS; affecting only the lungs) and extensive stage (ES; metastatic outside the thorax cavity). NSCLC, on the other hand, accounts for more than $80 \%$ of all lung cancers and is generally divided into nonmetastatic (Stages I and II), advanced with local confinement to the thoracic cavity (Stage III), and metastatic to other organs (Stage IV). Adenocarcinoma, squamous cell carcinoma, and large cell carcinoma are the most common types of NSCLC. ${ }^{(118-120)}$
In general, most of the SCLC cases dramatically respond to the chemotherapeutics. A high objective initial response rate (RR) ranging from $60 \%$ to $90 \%$ and a complete response (CR) ranging from $45 \%$ to $75 \%$ are observed in chemotherapy of LS-SCLC. However, the response durations are often short with high recurrence rates and a median survival of only 1.5 to 2 years. Combination chemotherapy of the ES-SCLC type even results in high RR with considerable objective responses and CR of $15 \%$ to $30 \%$. $^{(119)}$

In contrast to SCLCs, NSCLCs are relatively insensitive to the chemotherapeutics. However, chemotherapy is widely carried out as a neoadjuvant or adjuvant therapy in patients with higher risk. Moreover, $\sim 80 \%$ to $85 \%$ of the NSCLC cases are diagnosed at stages III and IV, which makes surgery inapplicable. Therefore, chemotherapy remains a treatment of choice for the locally advanced or metastatic NSCLCs, aiming at extending the survival rate and improving the quality of life. ${ }^{(119)}$

The majority of clinical trials investigating the inhalation delivery of therapeutics by nanocarriers have concentrated on treatment of NSCLC (Table 4) and other cancers metastatic to the lungs. The inhalational delivery seems appropriate mostly for targeting the primary lung tumors due to limited accessibility of this administration route to the secondary tumors metastasized from the lungs to other tissues. Therefore, the inhalational delivery may not be efficient in systemic treatment of most SCLC cases that are generally diagnosed at advanced stages due to their rapid metastasis at early stages. 
Table 3. Physical Properties of the Particles Containing Conjugated Ligands Targeting Lung Cancer Cells

\begin{tabular}{|c|c|c|c|c|c|c|c|}
\hline Compound & $\begin{array}{l}\text { Particle } \\
\text { size (nm) }\end{array}$ & $\begin{array}{c}\text { Zeta } \\
\text { potential }(\mathrm{mV})\end{array}$ & $\begin{array}{c}\text { Surface } \\
\text { functionality }\end{array}$ & $\begin{array}{c}\text { Chemo- } \\
\text { therapeutic }\end{array}$ & $\begin{array}{c}L C \\
(w t . \%)\end{array}$ & $E E(\%)$ & Ref. \\
\hline \multicolumn{8}{|l|}{ Ceramics } \\
\hline \multirow[t]{2}{*}{ Mesoporous silica } & 100 & & MPTES & DOX & & & (128) \\
\hline & 160 & & MPTES & CIS, DOX & & $\begin{array}{l}8 \text { DOX } \\
30 \text { CIS }\end{array}$ & (110) \\
\hline \multicolumn{8}{|l|}{ Metals } \\
\hline \multirow[t]{4}{*}{ Gold } & 44 & & PEG & & & & $(130)$ \\
\hline & 25 & -20.4 & & & & & (131) \\
\hline & 41 & -35.0 & PEG & & & & (141) \\
\hline & 338 & -13.7 & PEG & & & & (160) \\
\hline \multirow[t]{2}{*}{ Iron oxide } & $53-62$ & -8.0 to -4.2 & Sulfo-SMCC & & & & (138) \\
\hline & & & NHS-PEG-MAL & & & & (148) \\
\hline Gold-iron oxide & $\begin{array}{c}10 . J \\
73\end{array}$ & -29.0 & PEG & & & & (129) \\
\hline \multicolumn{8}{|l|}{ Lipids } \\
\hline \multirow[t]{5}{*}{ Liposome } & 116 & & PEG & & & & (132) \\
\hline & $130-150$ & $\sim 0$ & PEG & & & & (143) \\
\hline & 100 & -32.6 & DSPE-PEG-MAL & DOX & & & (155) \\
\hline & 303 & -2.7 & DSPE-PEG & & & & (152) \\
\hline & 160 & -40.0 & PLL-HA & & & & (146) \\
\hline \multirow[t]{2}{*}{ Lipid } & 30 & & PEG-MAL & & & & $(142)$ \\
\hline & 110 & $\sim 0$ & DSPE-PEG & DOX, PTX & 5 & & (5) \\
\hline \multicolumn{8}{|l|}{ Polymers } \\
\hline PEG & 147 & & & DHA & 10 & & (153) \\
\hline \multirow[t]{5}{*}{ PLGA } & 178 & & & CPT & & 86 & (133) \\
\hline & 80 & -50.0 & OCE & PTX & & $85-100$ & (134) \\
\hline & $286-303$ & -43.0 to -45.0 & Pluronic F127 & DOX & & $19-27$ & (157) \\
\hline & 11500 & & PEMA & DOX & & 86.5 & (111) \\
\hline & 108 & -21.3 & Lipid & DOX & & 92.48 & (154) \\
\hline \multirow[t]{2}{*}{ PEG-PLGA } & $149-186$ & -24.7 to -21.5 & & CIS, PTX & 4.68 & & (150) \\
\hline & 136 & 36.1 & & DOX & 7.3 & & (159) \\
\hline PEG-PLA & $80-100$ & -22.9 & MAL & PTX & & $<86$ & (158) \\
\hline \multirow{2}{*}{ TPGS-PLA } & 158 & & & & & & (144) \\
\hline & 162 & & & & & & (145) \\
\hline \multirow[t]{2}{*}{$\mathrm{CS}$} & 180 & -5.1 & & DMC & & 98 & (136) \\
\hline & 185 & 21.1 & PEG & GEM & & 37.2 & (151) \\
\hline CS- $\gamma$-PGA & 200 & -17.0 & & DTX & & 42 & (135) \\
\hline \multicolumn{8}{|l|}{ Gelatin } \\
\hline \multirow[t]{2}{*}{ Type A } & 220 & -9.3 & NeutrAvidin & & & & (67) \\
\hline & 120 & & NeutrAvidin & CIS & 20 & 90 & (64) \\
\hline \multicolumn{8}{|l|}{ Composites } \\
\hline DŚPE-PEG & $\sim 12$ & -15.7 & & & & & (147) \\
\hline PCL-Liposome & $150-180$ & -30 to -15 & DSPE-PEG & & & & (139) \\
\hline Lipid-CP & 20 & 10.0 & DSPE-PEG & GEM & & 75 & (162) \\
\hline
\end{tabular}

CIS, cisplatin; CP, calcium phosphate; CPT, capthothecin; CS, chitosan; DHA, dihydroartemisinin; DOX, doxorubicin; DMC, demethoxycurcumin; DSPE, distearoyl phosphoethanolamine; DTX, docetaxel; EE, encapsulation efficiency; GEM, gemcitabine; HA, hyaluronic acid; LC, loading capacity; MAL, maleimide; MPTS, mercaptopropyl trimethoxysilane; NHS-PEG-MAL, N-hydroxysuccinimide polyethylene glycol maleimide; OCE, oleyl cysteineamide; PCL, polycaprolactone; PEG, polyethylene glycol; PEMA, polyethylenealt-maleic anhydride; PGA, polyglutamic acid; PLA, polylactic acid; PLGA, polylactic-co-glycolic acid; PLL, poly-L lysine; PTX, paclitaxel; SMCC, succinimidyl maleimidomethyl cyclohexane carboxylate; TPGS, tocopheryl polyethylene glycol succinate.

The efficacy of this approach could even be less for the metastatic NSCLC due to their relatively low cell sensitivity to chemotherapeutics. Therefore, the inhalational delivery of nanocarriers containing chemotherapeutics is probably more efficient for targeting of the nonmetastatic and locally advanced NSCLC as well as combination therapies together with systemic treatment of secondary tumors metastasized into the lungs.

The clinical efficacy and safety of inhalational carriers of chemotherapeutics have been assessed in two clinical trials (Table 4). The maximum tolerated dose, safety profile, and pharmacokinetics of the inhaled lipid cisplatin (ILC) have been previously determined in a phase I dose-escalating study on patients with primary or metastatic lung carcinoma. ${ }^{(121)}$ The cisplatin and lipid (dipalmitoyl Phosphatidylcholine with MMAD of $3.7 \mu \mathrm{m}$ ) concentrations in this study were, respectively, 1.0 and $16 \mathrm{mg} / \mathrm{mL}$ in the aqueous solution. The administrated dosage of ILC was 1.5 to $60 \mathrm{mg} / \mathrm{m}^{2}$, nebulized for 1 to 4 consecutive days/week and 1 to 3 weeks/cycle.

Investigation of the safety profile up to the maximum deliverable dosage of $60 \mathrm{mg} / \mathrm{m}^{2}$ indicated no DLT such as hematologic, neurologic, auditory, or renal toxicities. 
Table 4. Clinical Trials on Inhalational Therapy of Different Lung Cancers

\begin{tabular}{|c|c|c|c|c|c|c|}
\hline Identifier & Year & Phase & Status & Device & Drug & Cancer type \\
\hline 00004930 & 2000 & I & Complete & Nebulizer & Doxorubicin & $\begin{array}{l}\text { NSCLC (recurrent, stage III, stage IV) } \\
\text { SCLC (recurrent, ES) } \\
\text { Lung metastatic cancers }\end{array}$ \\
\hline 00005610 & 2000 & II & Complete & Nebulizer $^{\mathrm{a}}$ & Sargramostim & Lung metastatic melanoma \\
\hline 00017121 & 2001 & $\mathrm{I}$ & Complete & Nebulizer & Sargramostim & Lung metastatic melanoma \\
\hline 00020124 & 2001 & I & Complete & OncoMyst $^{\mathrm{b}}$ & Doxorubicin & $\begin{array}{l}\text { NSCLC (recurrent, stage III, stage IV) } \\
\text { SCLC (recurrent, ES) } \\
\text { Lung metastatic cancers }\end{array}$ \\
\hline 00066365 & 2003 & II & Complete & Nebulizer & Sargramostim & Lung metastatic osteosarcoma \\
\hline 00082472 & 2004 & $\mathrm{I} / \mathrm{II}$ & Unknown & OncoMyst & $\begin{array}{l}\text { Doxorubicin, IV docetaxel, } \\
\text { cisplatin }\end{array}$ & NSCLC (stage III, stage IV) \\
\hline 00102531 & 2005 & $\mathrm{Ib} / \mathrm{IIa}$ & Complete & Nebulizer & Liposomal cisplatin & Lung metastatic osteosarcoma \\
\hline 00250120 & 2005 & I & Withdrawn & Nebulizer & Liposomal camptothecin & NSCLC (any stage) \\
\hline 00277082 & 2006 & $\mathrm{I} / \mathrm{II}$ & Complete & Nebulizer & Liposomal camptothecin & NSCLC (stage IV) \\
\hline 00652860 & 2008 & II & Complete & & $\begin{array}{l}\text { liposomal doxorubicin, } \\
\text { Sargramostim, cisplatin, } \\
\text { ifosfamide, mitomycin C }\end{array}$ & NSCLC (stage III) \\
\hline 01590069 & 2012 & $\mathrm{I} / \mathrm{II}$ & Ongoing & Nebulizer & Interleukin-2 & Lung metastatic osteosarcoma \\
\hline 01650090 & 2012 & II & Ongoing & Nebulizer & Liposomal cisplatin & Lung metastatic osteosarcoma \\
\hline 02009436 & 2013 & $\mathrm{I}$ & Recruiting & Nebulizer & Azacitidine & NSCLC (stage IV) \\
\hline
\end{tabular}

${ }^{a}$ Connected to a standard air compressor to generate the aerosol mist.

${ }^{\mathrm{b}}$ Consisted of a Pari LC Plus nebulizer placed inside a spray-capturing system.

NSCLC, nonsmall cell lung cancer; SCLC, small cell lung cancer.

Nausea, dyspnea, fatigue, vomiting, and hoarseness with grades 1 or 2 were the most widely observed AEs. However, a number of reversible local AEs such as decreases in the forced expiratory volume in one second and diffusing lung capacity for carbon monoxide, which are generally not seen during systemic administration of cisplatin, occurred with grades 1 to 2 after one course in few patients.

The pharmacokinetic studies showed a very low measurable systemic exposure to cisplatin only in three patients with the longest repeated inhalations (6.66-8 hours per week). The plasma concentration of cisplatin in two patients who received $48 \mathrm{mg} / \mathrm{m}^{2}$ ILC was $\sim 0.4-0.5 \mu \mathrm{M}$ after the last session, whereas this value was increased to around $1.4 \mu \mathrm{M}$ in the patient receiving $60 \mathrm{mg} / \mathrm{m}^{2}$ ILC. Therefore, ILC was found safe and feasible, leading to a stable disease in 12 out of 17 patients. ${ }^{(121)}$

Due to the encouraging results, a phase $\mathrm{Ib} / \mathrm{II} a$ clinical trial was further carried out to characterize the clinical performance of ILC in recurrent osteosarcoma patients with only pulmonary metastases. ${ }^{(31)}$ ILC was nebulized every 2 weeks with dosages of 24 or $36 \mathrm{mg} / \mathrm{m}^{2}$. The most common AEs were respiratory (e.g., cough, wheezing, nasal dryness, postnasal drip, and rhinorrhea), observed in 13 out of 19 patients, as well as gastrointestinal (e.g., nausea/vomiting) with grades 1 and 2. However, a patient was hospitalized due to a grade 3 vomiting after administration of $24 \mathrm{mg} / \mathrm{m}^{2}$ ILC. The hallmarks of systemic cisplatin administration such as hematologic toxicity, nephrotoxicity, ototoxicity, hearing loss, or long-term abnormalities in the pulmonary function testing (PFT) parameters were not observed in the patients. ${ }^{(31)}$

The platinum level in the tumor tissues of the patients who subsequently underwent metastasectomy ranged from 200 to $18,900 \mu \mathrm{g} / \mathrm{kg},{ }^{(31)}$ which was significantly higher than that measured after intravenous or intra-arterial administration of $150 \mathrm{mg} / \mathrm{m}^{2}$ cisplatin (from undetectable to $950 \mu \mathrm{g} / \mathrm{kg}){ }^{(122,123)}$ A low systemic exposure of the encapsulated cisplatin was again confirmed in this study, where its serum concentration 18-24 hours postdose $(47.0-153.5 \mathrm{ng} / \mathrm{mL})$ was significantly lower than that $(400$ $3500 \mathrm{ng} / \mathrm{mL}$ ) reported for intravenous administration of $100-120 \mathrm{mg} / \mathrm{m}^{2}$, which is the typical dosage in treatment of osteosarcoma. ${ }^{(124)}$

Investigation of therapeutic efficacy of ILC in recurrent osteosarcoma highlighted the significance of lesion size and necessity for surgical resection, ${ }^{(31)}$ where the patients with lesions smaller than $2 \mathrm{~cm}$ or those who underwent complete surgical resection had sustained benefits. Overall, among eight patients with small lesions, one patient achieved a CR radiographically, two patients experienced a stable disease in two cycles and CR after metastasectomy, one patient showed a sustained partial response, and the remaining had stable diseases. ${ }^{(31)}$

A clinical trial was also performed by using liposomal 9-nitrocamptothecin (9NC) with a droplet size of $1-3 \mu \mathrm{m}$ for treatment of primary or metastatic lung cancer. ${ }^{(125)}$ Various dosages, including 26.6, 20,13.3, and $6.7 \mu \mathrm{g} / \mathrm{kg}$ per day, were used to determine the optimal concentration with a sufficient clinical efficacy and minimal side effects. At 26.6 and $20 \mu \mathrm{g} / \mathrm{kg}$ per day, the DLTs were grade 3 chemical pharyngeal mucositis and fatigue, respectively. At dosage of $13.3 \mu \mathrm{g} / \mathrm{kg}$ per day, all patients tolerated the treatment well without a grade $3 \mathrm{AE}$. The most widely observed grade 2 $\mathrm{AE}$ was nausea, followed by cough, anemia, vomiting, wheezing, fatigue, peribuccal rash, and neutropenia.

The most remarkable finding of this study was the lack of hematological toxicity, which is widely observed when $9 \mathrm{NC}$ is used by oral administration. ${ }^{(126)}$ Therefore, a dosage of $13.3 \mu \mathrm{g} / \mathrm{kg}$ (equivalent to $0.5 \mathrm{mg} / \mathrm{m}^{2}$ ) per day was recommended for administration of liposomal 9NC via two consecutive 30-minute nebulizations per day from a nebulizer reservoir with $4 \mathrm{mg}$ of $9 \mathrm{NC}$ in $10 \mathrm{~mL}$ of sterile water for 8 weeks. The pharamacokintetic studies indicated postdose plasma concentrations of $9-\mathrm{NC}$ ranging from 32.0 to 
$120.4 \mathrm{ng} / \mathrm{mL}$, which was significantly narrower than that observed after its oral administration $(26-517 \mathrm{ng} / \mathrm{mL})$. However, the median values of postdose plasma concentration obtained using inhalational liposomal $9 \mathrm{NC}$ and oral cisplatin $\left(76.7 \pm 39.1\right.$ and $111 \mathrm{ng} / \mathrm{mL},{ }^{(126)}$ respectively) were not statistically significant.

The obtained clinical results showed the feasibility and safety of aerosol administration of liposomal 9NC and its potential in stabilization of the primary lung cancer in three out of the six patients. Moreover, partial remissions of the uterine cancer and liver metastasis were also observed, demonstrating the systemic potential of aerosol delivery of this drug.

Overall, the inhalational liposomal formulations carrying cisplatin or $9 \mathrm{NC}$ were demonstrated to be well tolerated and causing minimal changes in PFT, without typical toxicities associated with systemic administrations of these drugs. Moreover, given the complete or partials responses observed in the patients who received these products, inhalational delivery of chemotherapeutics using liposomes shows potential as an effective approach for inhibition of the micrometastases, treatments of various lung tumors, and prolonging the patients' life. ${ }^{(31)}$

\section{Other lung diseases}

A majority of patients (in particular the patients older than 70 years) with lung cancer also suffer from other lung diseases such as asthma, chronic obstructive pulmonary disease, bronchiectasis, and cystic fibrosis, which complicate deposition and absorption of therapeutics due to their crucial impact on the lung architecture.

A significant deformation of the bifurcation angles as well as obstruction of lung airways due to an increased mucus accumulation generally leads to decreased cross-sectional area and, subsequently, increased air velocity and turbulence. Turbulent flow of the aerosol could significantly affect the distribution and deposition profiles of the inhaled particles. Moreover, obstruction of the airway often occurs in the regions that require to be targeted by the therapeutic compounds to obtain an effective clinical outcome, ${ }^{(127)}$ whereas the airways obstruction navigates the inhaled aerosol to the unobstructed airways of the healthy regions, leading to a remarkably low drug deposition in the affected areas.

\section{Conclusion}

The pulmonary system is known as a promising route for local administration of chemotherapeutics, presenting a large surface area and low enzymatic activity. However, the lung clearance mechanisms, rapid metabolic degradation, as well as low control over the deposition rate and site of the inhaled therapeutics remain the major obstacles for successful pulmonary drug delivery.

Several approaches have been investigated to avoid the lung clearance mechanisms and to prolong half-life of the inhaled chemotherapeutics. In particular, the particle-based delivery systems have been shown as a promising solution for overcoming the physiological barriers present in the pulmonary system, thus enhancing the bioavailability of therapeutic compounds at lower lung regions.

The particle-based delivery systems must effectively evade the pulmonary clearance mechanisms, protect their cargo from rapid metabolic degradation, reduce the drug absorption, improve localized delivery to the tumor area, enhance the sustained release, decrease the dosage frequency, and minimize the systemic toxicity. To achieve these requirements, identification of the influence of different physicochemical parameters such as carrier composition, size, shape, and surface chemistry is imperative to tailor their biological behavior in the physiological environment. Understanding the critical characteristics, including particle-particle interactions, aggregation, proteins' adsorption on the particle surfaces, and their potential to provoke the immunological responses, is also beneficial to develop an effective pulmonary delivery system.

In spite of the great advances in the design and development of particle-based pulmonary systems, clinical translation of this approach for inhalation of chemotherapeutics in lung cancer therapy is still challenging. It is well known that the biophysical characteristics of the inhaled particles often differ crucially from those formulated during fabrication. This is mostly due to the particles' interaction with the proteins and lipids during contact with the lung lining fluid, which results in formation of biomolecular hard and soft coronas on the particles' surfaces. Therefore, it is the biomolecular corona that defines the biological behavior of the inhaled nanoparticles and thus becomes the major biological entity of the particles.

The corona type and density is significantly affected by the particles' characteristics such as composition, size, surface charge, and surface functionality. As a result, the majority of developed PPDS suffer from the short half-life and low bioavailability of the therapeutic agents at the target region, which cause inefficient therapeutic influence and adverse side effects. Therefore, synthesis of carriers with minimal absorption of proteins and lipids that allows escaping the various lung clearance mechanisms and provides prolonged deposition at target tissue remains extremely complicated.

Further research for detailed exploration and understanding of the lungs' function and molecular bases of the lung clearance mechanisms could aid in better overcoming of the biological barriers that the inhaled therapeutics encounter while reaching the deep lung areas. Once these barriers are successfully avoided, the patients could even receive their chemotherapeutic treatment at home with a cost-effective approach compared with the current standard treatment, resulting in reduced hospitalization cases.

Sufficient understanding of the critical influential parameters in particle-based pulmonary delivery of anticancer drugs could help in formulization and development of pulmonary delivery systems with higher safety and efficacy levels. Therefore, considerable effort is still required for eliminating the laboratory and clinical gaps and to enable translating the PPDS into the commercial therapeutic products.

\section{Acknowledgment}

This work was supported by LRGS NanoMite University of Malaya (Grant No: RU029-2014).

\section{Author Disclosure Statement}

No competing financial interests exist.

\section{References}

1. Ruge CA, Kirch J, and Lehr C-M: Pulmonary drug delivery: From generating aerosols to overcoming biological 
barriers-Therapeutic possibilities and technological challenges. Lancet Respir Med. 2013;1:402-413.

2. Darwiche K, Zarogoulidis P, Karamanos NK, Domvri K, Chatzaki E, Constantinidis TC, Kakolyris S, and Zarogoulidis $\mathrm{K}$ : Efficacy versus safety concerns for aerosol chemotherapy in non-small-cell lung cancer: A future dilemma for microoncology. Future Oncol. 2013;9:505-525.

3. Willis L, Hayes D, and Mansour HM: Therapeutic liposomal dry powder inhalation aerosols for targeted lung delivery. Lung. 2012;190:251-262.

4. Gaspar MM, Radomska A, Gobbo OL, Bakowsky U, Radomski MW, and Ehrhardt C: Targeted delivery of transferrin-conjugated liposomes to an orthotopic model of lung cancer in nude rats. J Aerosol Med Pulm Drug Deliv. 2012;25:310-318.

5. Taratula O, Kuzmov A, Shah M, Garbuzenko OB, and Minko T: Nanostructured lipid carriers as multifunctional nanomedicine platform for pulmonary co-delivery of anticancer drugs and siRNA. J Control Release. 2013;171:349357.

6. Mainelis G, Seshadri S, Garbuzenko OB, Han T, Wang Z, and Minko T: Characterization and application of a noseonly exposure chamber for inhalation delivery of liposomal drugs and nucleic acids to mice. J Aerosol Med Pulm Drug Deliv. 2013;26:345-354.

7. Song JM, Kirtane AR, Upadhyaya P, Qian X, Balbo S, Teferi F, Panyam J, and Kassie F: Intranasal delivery of liposomal indole-3-carbinol improves its pulmonary bioavailability. Int J Pharm. 2014;477:96-101.

8. Ozpolat B, Sood AK, and Lopez-Berestein G: Liposomal siRNA nanocarriers for cancer therapy. Adv Drug Deliv Rev. 2014;66:110-116.

9. Murata M, Tahara K, and Takeuchi H: Real-time in vivo imaging of surface-modified liposomes to evaluate their behavior after pulmonary administration. Eur J Pharm Biopharm. 2014;86:115-119.

10. Gandhi M, Pandya T, Gandhi R, Patel S, Mashru R, Misra $\mathrm{A}$, and Tandel $\mathrm{H}$ : Inhalable liposomal dry powder of gemcitabine- $\mathrm{HCl}$ : Formulation, in vitro characterization and in vivo studies. Int J Pharm. 2015;496:886-895.

11. Wei Y, Xue Z, Ye Y, Huang Y, and Zhao L: Paclitaxel targeting to lungs by way of liposomes prepared by the effervescent dispersion technique. Arch Pharm Res. 2013; 37:728-737.

12. Joshi S, Cooke JRN, Chan DKW, Ellis JA, Hossain SS, Singh-Moon RP, Wang M, Bigio IJ, Bruce JN, and Straubinger RM: Liposome size and charge optimization for intraarterial delivery to gliomas. Drug Deliv Transl Res. 2016;6:225-233.

13. Xia Y, Tian J, and Chen X: Effect of surface properties on liposomal siRNA delivery. Biomaterials. 2016;79:56-68.

14. Nguyen TX, Huang L, Gauthier M, Yang G, and Wang Q: Recent advances in liposome surface modification for oral drug delivery. Nanomedicine. 2016;11:1169-1185.

15. Nii T, and Ishii F: Encapsulation efficiency of water-soluble and insoluble drugs in liposomes prepared by the microencapsulation vesicle method. Int J Pharm. 2005;298:198-205.

16. Xu X, Khan MA, and Burgess DJ: Predicting hydrophilic drug encapsulation inside unilamellar liposomes. Int $\mathbf{J}$ Pharm. 2012;423:410-418.

17. Kong F, Zhang X, and Hai M: Microfluidics fabrication of monodisperse biocompatible phospholipid vesicles for encapsulation and delivery of hydrophilic drug or active compound. Langmuir. 2014;30:3905-3912.
18. Bhardwaj U, and Burgess DJ: Physicochemical properties of extruded and non-extruded liposomes containing the hydrophobic drug dexamethasone. Int J Pharm. 2010;388:181189.

19. Panwar P, Pandey B, Lakhera PC, and Singh KP: Preparation, characterization, and in vitro release study of albendazole-encapsulated nanosize liposomes. Int $\mathrm{J}$ Nanomedicine. 2010;5:101-108.

20. Cupri S, Graziano AC, Cardile V, Skwarczynski M, Toth I, and Pignatello R: A study on the encapsulation of an occludin lipophilic derivative in liposomal carriers. J Liposome Res. 2015;25:287-293.

21. Pignatello R, Musumeci T, Graziano AC, Lo Furno D, Varamini P, Mansfeld FM, Cardile V, and Toth I: A study on liposomal encapsulation of a lipophilic prodrug of LHRH. Pharm Dev Technol. 2015;21:664-671.

22. Patil JS, Devi VK, Devi K, and Sarasija S: A novel approach for lung delivery of rifampicin-loaded liposomes in dry powder form for the treatment of tuberculosis. Lung India. 2015;32:331-338.

23. Chattopadhyay S: Aerosol generation using nanometer liposome suspensions for pulmonary drug delivery applications. J Liposome Res. 2013;23:255-267.

24. Liu C, Shi J, Dai Q, Yin X, Zhang X, and Zheng A: In-vitro and in-vivo evaluation of ciprofloxacin liposomes for pulmonary administration. Drug Dev Indl Pharm. 2015;41:272278.

25. Unida S, Ito $\mathrm{Y}$, Onodera R, Tahara K, and Takeuchi H: Inhalation properties of water-soluble drug loaded liposomes atomized by nebulizer. Asian J Pharm Sci. 2016;11:205-206.

26. Anabousi S, Bakowsky U, Schneider M, Huwer H, Lehr C$\mathrm{M}$, and Ehrhardt C: In vitro assessment of transferrinconjugated liposomes as drug delivery systems for inhalation therapy of lung cancer. Eur J Pharm Sci. 2006;29:367-374.

27. Garbuzenko OB, Saad M, Betigeri S, Zhang M, Vetcher AA, Soldatenkov VA, Reimer DC, Pozharov VP, and Minko T: Intratracheal versus intravenous liposomal delivery of sirna, antisense oligonucleotides and anticancer drug. Pharm Res. 2008;26:382-394.

28. Garbuzenko OB, Mainelis G, Taratula O, and Minko T: Inhalation treatment of lung cancer: The influence of composition, size and shape of nanocarriers on their lung accumulation and retention. Cancer Bio Med. 2014;11:44-55.

29. Videira M, Almeida AJ, and Fabra À: Preclinical evaluation of a pulmonary delivered paclitaxel-loaded lipid nanocarrier antitumor effect. Nanomedicine. 2012;8:1208-1215.

30. Patel AR, Chougule MB, I T, Patlolla R, Wang G, and Singh M: Efficacy of aerosolized celecoxib encapsulated nanostructured lipid carrier in non-small cell lung cancer in combination with docetaxel. Pharm Res. 2013;30:14351446.

31. Chou AJ, Gupta R, Bell MD, Riewe KOD, Meyers PA, and Gorlick R: Inhaled lipid cisplatin (ILC) in the treatment of patients with relapsed/progressive osteosarcoma metastatic to the lung. Pediatr Blood Cancer. 2013;60:580-586.

32. Weber S, Zimmer A, and Pardeike J: Solid lipid nanoparticles (SLN) and nanostructured lipid carriers (NLC) for pulmonary application: A review of the state of the art. Eur J Pharm Biopharm. 2014;86:7-22.

33. Kaur P, Garg T, Rath G, Murthy RSR, and Goyal AK: Development, optimization and evaluation of surfactantbased pulmonary nanolipid carrier system of paclitaxel for the management of drug resistance lung cancer using BoxBehnken design. Drug Deliv. 2014;23:1912-1925. 
34. Ponte BM, Santos IS, Macedo AS, and Souto EB: Lipid nanoplatforms for pulmonary drug delivery. In: JL Arias, (ed). Nanotechnology and Drug Delivery. Vol 2: NanoEngineering Strategies and Nanomedicines against Severe Diseases. CRC Press, Tailor \& Francis Group, Boca Raton, FL; pp. 146-164, 2016.

35. Dharmala K, Yoo JW, and Lee CH: Development of chitosan-SLN microparticles for chemotherapy: In vitro approach through efflux-transporter modulation. J Control Release. 2008;131:190-197.

36. Patlolla RR, Chougule M, Patel AR, Jackson T, Tata PN, and Singh M: Formulation, characterization and pulmonary deposition of nebulized celecoxib encapsulated nanostructured lipid carriers. J Control Release. 2010;144:233-241.

37. Videira MA, Gano L, Santos C, Neves M, and Almeida AJ: Lymphatic uptake of lipid nanoparticles following endotracheal administration. J Microencapsul. 2006;23:855-862.

38. Hong S-S, Kim SH, and Lim S-J: Effects of triglycerides on the hydrophobic drug loading capacity of saturated phosphatidylcholine-based liposomes. Int J Pharm. 2015; 483:142-150.

39. Kannan V, Balabathula P, Divi MK, Thoma LA, and Wood GC: Optimization of drug loading to improve physical stability of paclitaxel-loaded long-circulating liposomes. J Liposome Res. 2015;25:308-315.

40. Mayer LD, Tai LCL, Ko DSC, Masin D, Ginsberg RS, Cullis PR, and Bally MB: Influence of vesicle size, lipid composition, and drug-to-lipid ratio on the biological activity of liposomal doxorubicin in mice. Cancer Res. 1989;49:5922-5930.

41. Kulkarni SB, Betageri GV, and Singh M: Factors affecting microencapsulation of drugs in liposomes. J Microencapsul. 1995;12:229-246.

42. Nagayasu A, Uchiyama K, and Kiwada H: The size of liposomes: A factor which affects their targeting efficiency to tumors and therapeutic activity of liposomal antitumor drugs. Adv Drug Deliv Rev. 1999;40:75-87.

43. Drummond DC, Meyer O, Hong K, Kirpotin DB, and Papahadjopoulos D: Optimizing liposomes for delivery of chemotherapeutic agents to solid tumors. Pharmacol Rev. 1999;51:691-744.

44. Biswas S, Dodwadkar NS, Deshpande PP, and Torchilin VP: Liposomes loaded with paclitaxel and modified with novel triphenylphosphonium-PEG-PE conjugate possess low toxicity, target mitochondria and demonstrate enhanced antitumor effects in vitro and in vivo. $\mathrm{J}$ Control Release. 2012;159:393-402.

45. Park J-H, Cho H-J, Yoon HY, Yoon I-S, Ko S-H, Shim JS, Cho J-H, Park JH, Kim K, Kwon IC, and Kim D-D: Hyaluronic acid derivative-coated nanohybrid liposomes for cancer imaging and drug delivery. J Control Release. 2014;174:98-108.

46. Canonico AE, Conary JT, Meyrick BO, and Brigham KL: Aerosol and intravenous transfection of human alpha 1antitrypsin gene to lungs of rabbits. Am J Respir Cell Mol Biol. 1994;10:24-29.

47. Koshkina VN, Gilbert EB, Waldrep CJ, Seryshev A, and Knight V: Distribution of camptothecin after delivery as a liposome aerosol or following intramuscular injection in mice. Cancer Chemother Pharmacol. 1999;44:187-192.

48. Jensen DMK, Cun D, Maltesen MJ, Frokjaer S, Nielsen HM, and Foged C: Spray drying of siRNA-containing PLGA nanoparticles intended for inhalation. J Control Release. 2010;142:138-145.
49. Kim I, Byeon HJ, Kim TH, Lee ES, Oh KT, Shin BS, Lee $\mathrm{KC}$, and Youn YS: Doxorubicin-loaded highly porous large PLGA microparticles as a sustained- release inhalation system for the treatment of metastatic lung cancer. Biomaterials. 2012;33:5574-5583.

50. Shi X, Li C, Gao S, Zhang L, Han H, Zhang J, Shi W, and Li Q: Combination of doxorubicin-based chemotherapy and polyethylenimine/p53 gene therapy for the treatment of lung cancer using porous PLGA microparticles. Colloids Surf B Biointerfaces. 2014;122:498-504.

51. Feng T, Tian H, Xu C, Lin L, Xie Z, Lam MH-W, Liang $\mathrm{H}$, and Chen X: Synergistic co-delivery of doxorubicin and paclitaxel by porous PLGA microspheres for pulmonary inhalation treatment. Eur J Pharm Biopharm. 2014;88:10861093.

52. Bayard FJC, Thielemans W, Pritchard DI, Paine SW, Young SS, Bäckman P, Ewing $\mathrm{P}$, and Bosquillon C: Polyethylene glycol-drug ester conjugates for prolonged retention of small inhaled drugs in the lung. J Control Release. 2013;171:234-240.

53. Tawfeek HM, Evans AR, Iftikhar A, Mohammed AR, Shabir A, Somavarapu S, Hutcheon GA, and Saleem IY: Dry powder inhalation of macromolecules using novel PEG-co-polyester microparticle carriers. Int J Pharm. 2013;441:611-619.

54. Jin H, Kim TH, Hwang S-K, Chang S-H, Kim HW, Anderson HK, Lee H-W, Lee K-H, Colburn NH, Yang $\mathrm{H}-\mathrm{S}$, Cho M-H, and Cho CS: Aerosol delivery of urocanic acid-modified chitosan/programmed cell death 4 complex regulated apoptosis, cell cycle, and angiogenesis in lungs of K-ras null mice. Mol Cancer Ther. 2006;5:1041-1049.

55. Yang R, Yang S-G, Shim W-S, Cui F, Cheng G, Kim I-W, Kim D-D, Chung S-J, and Shim C-K: Lung-specific delivery of paclitaxel by chitosan-modified PLGA nanoparticles via transient formation of microaggregates. J Pharm Sci. 2009;98:970-984.

56. Okamoto H, Shiraki K, Yasuda R, Danjo K, and Watanabe Y: Chitosan-interferon- $\beta$ gene complex powder for inhalation treatment of lung metastasis in mice. J Control Release. 2011;150:187-195.

57. Singh D, Lohade A, Parmar J, Hegde DD, Soni P, Samad A, and Menon MD: Development of chitosan-based dry powder inhalation system of cisplatin for lung cancer. Indian J Pharm Sci. 2012;74:521-526.

58. Azarmi S, Tao X, Chen H, Wang Z, Finlay WH, Löbenberg R, and Roa WH: Formulation and cytotoxicity of doxorubicin nanoparticles carried by dry powder aerosol particles. Int J Pharm. 2006;319:155-161.

59. Hitzman CJ, Wattenberg LW, and Wiedmann TS: Pharmacokinetics of 5-fluorouracil in the hamster following inhalation delivery of lipid-coated nanoparticles. J Pharm Sci. 2006;95:1196-1211.

60. Andrade F, Neves Jd, Gener P, Schwartz Jr S, Ferreira D, Oliva M, and Sarmento B: Biological assessment of selfassembled polymeric micelles for pulmonary administration of insulin. Nanomedicine. 2015;11:1621-1631.

61. Rosière R, Van Woensel M, Mathieu V, Langer I, Mathivet T, Vermeersch M, Amighi K, and Wauthoz N: Development and evaluation of well-tolerated and tumor-penetrating polymeric micelle-based dry powders for inhaled anticancer chemotherapy. Int J Pharm. 2016;501:148-159.

62. Tong S-W, Xiang B, Dong D-W, and Qi X-R: Enhanced antitumor efficacy and decreased toxicity by self-associated 
docetaxel in phospholipid-based micelles. Int $\mathbf{J}$ Pharm. 2012;434:413-419.

63. Kaminskas LM, McLeod VM, Ryan GM, Kelly BD, Haynes JM, Williamson M, Thienthong N, Owen DJ, and Porter CJ: Pulmonary administration of a doxorubicinconjugated dendrimer enhances drug exposure to lung metastases and improves cancer therapy. J Control Release. 2014;183:18-26.

64. Long J-T, Cheang T-Y, Zhuo S-Y, Zeng R-F, Dai Q-S, Li H-P, and Fang S: Anticancer drug-loaded multifunctional nanoparticles to enhance the chemotherapeutic efficacy in lung cancer metastasis. J Nanobiotechnol. 2014;12:37.

65. Tseng C-L, Wu SY-H, Wang W-H, Peng C-L, Lin F-H, Lin C-C, Young T-H, and Shieh M-J: Targeting efficiency and biodistribution of biotinylated-EGF-conjugated gelatin nanoparticles administered via aerosol delivery in nude mice with lung cancer. Biomaterials. 2008;29:3014-3022.

66. Tseng C-L, Su W-Y, Yen K-C, Yang K-C, and Lin F-H: The use of biotinylated-EGF-modified gelatin nanoparticle carrier to enhance cisplatin accumulation in cancerous lungs via inhalation. Biomaterials. 2009;30:34763485 .

67. Tseng C-L, Wang T-W, Dong G-C, Yueh-Hsiu Wu S, Young T-H, Shieh M-J, Lou P-J, and Lin F-H: Development of gelatin nanoparticles with biotinylated EGF conjugation for lung cancer targeting. Biomaterials. 2007; 28:3996-4005.

68. Bosquillon C, Lombry C, Préat V, and Vanbever R: Influence of formulation excipients and physical characteristics of inhalation dry powders on their aerosolization performance. J Control Release. 2001;70:329-339.

69. Musante CJ, Schroeter JD, Rosati JA, Crowder TM, Hickey AJ, and Martonen TB: Factors affecting the deposition of inhaled porous drug particles. J Pharm Sci. 2002;91:1590-1600.

70. Labiris NR and Dolovich MB: Pulmonary drug delivery. Part I: Physiological factors affecting therapeutic effectiveness of aerosolized medications. Br J Clin Pharmacol. 2003;56:588-599.

71. Bosquillon C, Rouxhet PG, Ahimou F, Simon D, Culot C, Préat V, and Vanbever R: Aerosolization properties, surface composition and physical state of spray-dried protein powders. J Control Release. 2004;99:357-367.

72. Minne A, Boireau H, Horta MJ, and Vanbever R: Optimization of the aerosolization properties of an inhalation dry powder based on selection of excipients. Eur J Pharm Biopharm. 2008;70:839-844.

73. Smola M, Vandamme T, and Sokolowski A: Nanocarriers as pulmonary drug delivery systems to treat and to diagnose respiratory and nonrespiratory diseases. Int $\mathbf{J} \mathrm{Na}-$ nomed. 2008;3:1-19.

74. El-Sherbiny IM, Villanueva DG, Herrera D, and Smyth HDC: Overcoming lung clearance mechanisms for controlled release drug delivery. In: DCH Smyth and JA Hickey, (eds). Controlled Pulmonary Drug Delivery. Springer New York, New York, NY; pp. 101-126, 2011.

75. Usmani OS, Biddiscombe MF, and Barnes PJ: Regional lung deposition and bronchodilator response as a function of $\beta 2$-agonist particle size. Am J Respir Crit Care Med. 2005; 172:1497-1504.

76. Lee W-H, Loo C-Y, Traini D, and Young PM: Inhalation of nanoparticle-based drug for lung cancer treatment: Advantages and challenges. Asian J Pharm Sci. 2015;10:481489.
77. Yang W, Peters JI, and Williams RO: Inhaled nanoparticlesA current review. Int J Pharm. 2008;356:239-247.

78. Kumar A, Bicer EM, Pfeffer P, Monopoli M, Dawson K, Blomberg A, Behndig A, Dailey LA, Forbes B, and Mudway I: Inhaled nanoparticles develop a complex protein corona of biological importance. J Aerosol Med Pulm Drug Deliv. 2015;28:A3-A4.

79. Kumar A, Bicer EM, Morgan AB, Pfeffer PE, Monopoli M, Dawson KA, Eriksson J, Edwards K, Lynham S, Arno M, Behndig AF, Blomberg A, Somers G, Hassall D, Dailey LA, Forbes B, and Mudway IS: Enrichment of immunoregulatory proteins in the biomolecular corona of nanoparticles within human respiratory tract lining fluid. Nanomedicine. 2016;12:1033-1043.

80. Sham JOH, Zhang Y, Finlay WH, Roa WH, and Löbenberg R: Formulation and characterization of spray-dried powders containing nanoparticles for aerosol delivery to the lung. Int J Pharm. 2004;269:457-467.

81. Li Y-Z, Sun X, Gong T, Liu J, Zuo J, and Zhang Z-R: Inhalable microparticles as carriers for pulmonary delivery of thymopentin-loaded solid lipid nanoparticles. Pharm Res. 2010;27:1977-1986.

82. Okamoto H, Nishida S, Todo H, Sakakura Y, Iida K, and Danjo K: Pulmonary gene delivery by chitosan-pDNA complex powder prepared by a supercritical carbon dioxide process. J Pharm Sci. 2003;92:371-380.

83. El-Sherbiny IM, and Smyth HD: Biodegradable nanomicro carrier systems for sustained pulmonary drug delivery:(I) self-assembled nanoparticles encapsulated in respirable/swellable semi-IPN microspheres. Int J Pharm. 2010;395:132-141.

84. El-Sherbiny IM, McGill S, and Smyth HDC: Swellable microparticles as carriers for sustained pulmonary drug delivery. J Pharm Sci. 2010;99:2343-2356.

85. Champion JA, and Mitragotri S: Role of target geometry in phagocytosis. Proc Natl Acad Sci USA. 2006;103: 4930-4934.

86. Champion JA, and Mitragotri S: Shape induced inhibition of phagocytosis of polymer particles. Pharm Res. 2009;26: 244-249.

87. Jacobs C, and Müller RH: Production and characterization of a budesonide nanosuspension for pulmonary administration. Pharm Res. 2002;19:189-194.

88. Honary S, and Zahir F: Effect of zeta potential on the properties of nano-drug delivery systems-a review (Part 2). Trop J Pharm Res. 2013;12:265-273.

89. Ensign LM, Schneider C, Suk JS, Cone R, and Hanes J: Mucus penetrating nanoparticles: Biophysical tool and method of drug and gene delivery. Adv Mater. 2012;24: 3887-3894.

90. Evora C, Soriano I, Rogers RA, Shakesheff KM, Hanes J, and Langer R: Relating the phagocytosis of microparticles by alveolar macrophages to surface chemistry: The effect of 1,2-dipalmitoylphosphatidylcholine. J Control Release. 1998;51:143-152.

91. Surendrakumar K, Martyn GP, Hodgers ECM, Jansen M, and Blair JA: Sustained release of insulin from sodium hyaluronate based dry powder formulations after pulmonary delivery to beagle dogs. J Control Release. 2003;91:385-394.

92. Muralidharan P, Mallory E, Malapit M, Hayes Jr D, and Mansour HM: Inhalable PEGylated phospholipid nanocarriers and PEGylated therapeutics for respiratory delivery as aerosolized colloidal dispersions and dry powder inhalers. Pharmaceutics. 2014;6:333-353. 
93. Newman SM, Colbern TG, Working KP, Engbers C, and Amantea AM: Comparative pharmacokinetics, tissue distribution, and therapeutic effectiveness of cisplatin encapsulated in long-circulating, pegylated liposomes (SPI-077) in tumorbearing mice. Cancer Chemother Pharmacol. 1999;43:1-7.

94. Meenach SA, Anderson KW, Hilt JZ, McGarry RC, and Mansour HM: Characterization and aerosol dispersion performance of advanced spray-dried chemotherapeutic PEGylated phospholipid particles for dry powder inhalation delivery in lung cancer. Eur J Pharm Sci. 2013;49: 699-711.

95. Steckel H, and Bolzen N: Alternative sugars as potential carriers for dry powder inhalations. Int J Pharm. 2004; 270:297-306.

96. Klink DT, Chao S, Glick MC, and Scanlin TF: Nuclear translocation of lactosylated poly-L-lysine/cDNA complex in cystic fibrosis airway epithelial cells. Mol Ther. 2001;3:831-841.

97. Labiris NR, and Dolovich MB: Pulmonary drug delivery. Part II: The role of inhalant delivery devices and drug formulations in therapeutic effectiveness of aerosolized medications. Br J Clin Pharmacol. 2003;56:600-612.

98. Kawashima Y, Serigano T, Hino T, Yamamoto H, and Takeuchi $\mathrm{H}$ : A new powder design method to improve inhalation efficiency of pranlukast hydrate dry powder aerosols by surface modification with hydroxypropylmethylcellulose phthalate nanospheres. Pharm Res. 1998;15:1748-1752.

99. Mehmood RK: Review of cisplatin and oxaliplatin in current immunogenic and monoclonal antibody treatments. Oncol Rev. 2014;8:256.

100. Sousa GFd, Wlodarczyk SR, and Monteiro G: Carboplatin: Molecular mechanisms of action associated with chemoresistance. Braz J Pharmaceut Sci. 2014;50:693-701.

101. Hall MD, Telma KA, Chang K-E, Lee TD, Madigan JP, Lloyd JR, Goldlust IS, Hoeschele JD, and Gottesman MM: Say no to DMSO: Dimethylsulfoxide inactivates cisplatin, carboplatin and other platinum complexes. Cancer Res. 2014;74:3913-3922.

102. Johnstone TC, Suntharalingam K, and Lippard SJ: The next generation of platinum drugs: Targeted Pt(II) agents, nanoparticle delivery, and Pt(IV) prodrugs. Chem Rev. 2016;116:3436-3486.

103. Hartmann JT, and Lipp H-P: Toxicity of platinum compounds. Expert Opin Pharmacother. 2003;4:889-901.

104. Yu J, Xiao J, Yang Y, and Cao B: Oxaliplatin-based doublets versus cisplatin or carboplatin-based doublets in the first-line treatment of advanced nonsmall cell lung cancer. Medicine. 2015;94:e1072.

105. Noonan KL, Ho C, Laskin J, and Murray N: The influence of the evolution of first-line chemotherapy on steadily improving survival in advanced non-small-cell lung cancer clinical trials. J Thorac Oncol. 2015;10:1523-1531.

106. Li M, Huang H, Tan J, and Lin D: A randomized clinical trial on taxol plus oxaliplatin versus taxol plus cisplatin as first-line treatment in advanced non-small cell lung cancer. Chin J Lung Cancer. 2006;9:452-454.

107. Bidoli P, Zilembo N, Cortinovis D, Mariani L, Isa L, Aitini E, Cullurà D, Pari F, Nova $\mathrm{P}$, Mancin M, Formisano $\mathrm{B}$, and Bajetta E: Randomized phase II three-arm trial with three platinum-based doublets in metastatic nonsmall-cell lung cancer. An Italian Trials in Medical Oncology study. Ann Oncol. 2007;18:461-467.

108. Li Z, Hou M, Wang H, and Wang Z: A randomized study of gemcitabine plus oxaliplatin versus gemcitabine plus cisplatin as the 1st line chemotherapy for advanced nonsmall cell lung cancer in elderly patients. Chin J Lung Cancer. 2011;14:588-592.

109. In GK, and Nieva J: Emerging chemotherapy agents in lung cancer: Nanoparticles therapeutics for non-small cell lung cancer. Transl Cancer Res. 2015;4:340-355.

110. Taratula O, Garbuzenko OB, Chen AM, and Minko T: Innovative strategy for treatment of lung cancer: Targeted nanotechnology-based inhalation co-delivery of anticancer drugs and siRNA. J Drug Target. 2011;19:900-914.

111. Kim I, Byeon HJ, Kim TH, Lee ES, Oh KT, Shin BS, Lee $\mathrm{KC}$, and Youn YS: Doxorubicin-loaded porous PLGA microparticles with surface attached TRAIL for the inhalation treatment of metastatic lung cancer. Biomaterials. 2013;34:6444-6453.

112. Diego De M, Ana G-L, José María A, Sandra E-A, Roberto P-C, Celia del A, Luis José F, Ignacio O, Alberto A, and Luis M-L: TRAIL-coated lipid-nanoparticles overcome resistance to soluble recombinant TRAIL in non-small cell lung cancer cells. Nanotechnology. 2016;27:185101.

113. Le VNP, Leterme P, Gayot A, and Flament MP: Aerosolization potential of cyclodextrins-Influence of the operating conditions. PDA J Pharm Sci Technol. 2006;60: 314-322.

114. Ong HX, Traini D, Loo C-Y, Sarkissian L, Lauretani G, Scalia S, and Young PM: Is the cellular uptake of respiratory aerosols delivered from different devices equivalent? Eur J Pharm Biopharm. 2015;93:320-327.

115. Dhand R, Dolovich M, Chipps B, Myers TR, Restrepo R, and Rosen Farrar $\mathrm{J}$ : The role of nebulized therapy in the management of COPD: Evidence and recommendations. COPD. 2012;9:58-72.

116. Kaialy W, and Nokhodchi A: Dry powder inhalers: Physicochemical and aerosolization properties of several sizefractions of a promising alterative carrier, freeze-dried mannitol. Eur J Pharm Sci. 2015;68:56-67.

117. Zainudin BM, Biddiscombe M, Tolfree SE, Short M, and Spiro SG: Comparison of bronchodilator responses and deposition patterns of salbutamol inhaled from a pressurised metered dose inhaler, as a dry powder, and as a nebulised solution. Thorax. 1990;45:469-473.

118. Ahmad J, Akhter S, Rizwanullah M, Amin S, Rahman M, Ahmad MZ, Rizvi MA, Kamal MA, and Ahmad FJ: Nanotechnology-based inhalation treatments for lung cancer: State of the art. Nanotechnol Sci Appl. 2015;8:55-66.

119. Landesman-Milo D, Ramishetti S, and Peer D: Nanomedicine as an emerging platform for metastatic lung cancer therapy. Cancer Metastasis Rev. 2015;34:291-301.

120. Lee HY, Mohammed KA, and Nasreen N: Nanoparticlebased targeted gene therapy for lung cancer. Am J Cancer Res. 2016;6:1118-1134.

121. Wittgen BP, Kunst PW, Van Der Born K, Van Wijk AW, Perkins W, Pilkiewicz FG, Perez-Soler R, Nicholson S, Peters GJ, and Postmus PE: Phase I study of aerosolized SLIT cisplatin in the treatment of patients with carcinoma of the lung. Clin Cancer Res. 2007;13:2414-2421.

122. Jaffe N, Knapp J, Chuang VP, Wallace S, Ayala A, Murray J, Cangir A, Wang A, and Benjamin RS: Osteosarcoma: Intra-arterial treatment of the primary tumor with cis-diammine-dichloroplatinum II (CDP): Angiographic, pathologic, and pharmacologic studies. Cancer. 1983;51:402-407.

123. Bielack SS, Erttmann R, Looft G, Purfürst C, Delling G, Winkler K, and Landbeck G: Platinum disposition after 
intraarterial and intravenous infusion of cisplatin for osteosarcoma. Cancer Chemother Pharmacol. 1989;24:376380.

124. Kelsen DP, Alcock N, and Young CW: Cisplatin nephrotoxicity. Correlation with plasma platinum concentrations. Am J Clin Oncol. 1985;8:77-80.

125. Verschraegen CF, Gilbert BE, Loyer E, Huaringa A, Walsh G, Newman RA, and Knight V: Clinical evaluation of the delivery and safety of aerosolized liposomal 9-nitro20 (s)-camptothecin in patients with advanced pulmonary malignancies. Clin Cancer Res. 2004;10:2319-2326.

126. Verschraegen CF, Natelson EA, Giovanella BC, Kavanagh JJ, Kudelka AP, Freedman RS, Edwards CL, Ende $\mathrm{K}$, and Stehlin JS: A phase I clinical and pharmacological study of oral 9-nitrocamptothecin, a novel water-insoluble topoisomerase I inhibitor. Anticancer Drug. 1998;9: 36-44.

127. Zarogoulidis P, Chatzaki E, Porpodis K, Domvri K, Hohenforst-Schmidt W, Goldberg EP, Karamanos N, and Zarogoulidis $\mathrm{K}$ : Inhaled chemotherapy in lung cancer: Future concept of nanomedicine. Int $\mathrm{J}$ Nanomedicine. 2012;7:1551-1572.

128. Wang Y, Huang H-Y, Yang L, Zhang Z, and Ji H: Cetuximab-modified mesoporous silica nano-medicine specifically targets EGFR-mutant lung cancer and overcomes drug resistance. Sci Rep. 2016;6:25468.

129. Yokoyama T, Tam J, Kuroda S, Scott AW, Aaron J, Larson T, Shanker M, Correa AM, Kondo S, and Roth JA: EGFR-targeted hybrid plasmonic magnetic nanoparticles synergistically induce autophagy and apoptosis in nonsmall cell lung cancer cells. PLoS One. 2011;6:e25507.

130. Kao H-W, Lin Y-Y, Chen C-C, Chi K-H, Tien D-C, Hsia C-C, Lin W-J, Chen F-D, Lin M-H, and Wang H-E: Biological characterization of cetuximab-conjugated gold nanoparticles in a tumor animal model. Nanotechnology. 2014;25:295102.

131. Qian Y, Qiu M, Wu Q, Tian Y, Zhang Y, Gu N, Li S, Xu L, and Yin R: Enhanced cytotoxic activity of cetuximab in EGFR-positive lung cancer by conjugating with gold nanoparticles. Sci Rep. 2014;4:7490.

132. Gao M, Su H, Lin G, Li S, Yu X, Qin A, Zhao Z, Zhang Z, and Tang BZ: Targeted imaging of EGFR overexpressed cancer cells by brightly fluorescent nanoparticles conjugated with cetuximab. Nanoscale. 2016;8:15027-15032.

133. Deepagan VG, Sarmento B, Menon D, Nascimento A, Jayasree A, Sreeranganathan M, Koyakutty M, Nair SV, and Rangasamy J: In vitro targeted imaging and delivery of camptothecin using cetuximab-conjugated multifunctional PLGA-ZnS nanoparticles. Nanomedicine. 2012;7:507-519.

134. Karra N, Nassar T, Ripin AN, Schwob O, Borlak J, and Benita S: Antibody conjugated PLGA nanoparticles for targeted delivery of paclitaxel palmitate: Efficacy and biofate in a lung cancer mouse model. Small. 2013;9:42214236.

135. Maya S, Sarmento B, Lakshmanan V-K, Menon D, Seabra $\mathrm{V}$, and Jayakumar R: Chitosan cross-linked docetaxel loaded EGF receptor targeted nanoparticles for lung cancer cells. Int J Biol Macromol. 2014;69:532-541.

136. Huang W-T, Larsson M, Wang Y-J, Chiou S-H, Lin H-Y, and Liu D-M: Demethoxycurcumin-carrying chitosanantibody core-shell nanoparticles with multitherapeutic efficacy toward malignant A549 lung tumor: From in vitro characterization to in vivo evaluation. Mol Pharm. 2015; $12: 1242-1249$.
137. Lukianova-Hleb EY, Ren X, Constantinou PE, Danysh BP, Shenefelt DL, Carson DD, Farach-Carson MC, Kulchitsky VA, Wu X, Wagner DS, and Lapotko DO: Improved cellular specificity of plasmonic nanobubbles versus nanoparticles in heterogeneous cell systems. PLoS One. 2012; 7:e34537.

138. Jo S-M, Noh S-h, Jin Z, Lim Y, Cheon J, and Kim H-S: Simple and efficient capture of EGFR-expressing tumor cells using magnetic nanoparticles. Sens Actuators B Chem. 2014;201:144-152.

139. Mandal B, Mittal NK, Balabathula P, Thoma LA, and Wood GC: Development and in vitro evaluation of coreshell type lipid-polymer hybrid nanoparticles for the delivery of erlotinib in non-small cell lung cancer. Eur J Pharm Sci. 2016;81:162-171.

140. Lam ATN, Yoon J, Ganbold E-O, Singh DK, Kim D, Cho K-H, Lee SY, Choo J, Lee K, and Joo S-W: Colloidal gold nanoparticle conjugates of gefitinib. Colloids Surf B Biointerfaces. 2014;123:61-67.

141. Coelho SC, Almeida GM, Pereira MC, Santos-Silva F, and Coelho MA: Functionalized gold nanoparticles improve afatinib delivery into cancer cells. Expert Opin Drug Deliv. 2016;13:133-141.

142. Jin H, Lovell JF, Chen J, Ng K, Cao W, Ding L, Zhang Z, and Zheng G: Investigating the specific uptake of EGFconjugated nanoparticles in lung cancer cells using fluorescence imaging. Cancer Nanotechnol. 2010;1:71-78.

143. Kim SK, and Huang L: Nanoparticle delivery of a peptide targeting EGFR signaling. J Control Release. 2012;157: 279-286.

144. de Melo-Diogo D, Gaspar VM, Costa EC, Moreira AF, Oppolzer D, Gallardo E, and Correia IJ: Combinatorial delivery of Crizotinib-Palbociclib-Sildenafil using TPGSPLA micelles for improved cancer treatment. Eur J Pharm Biopharm. 2014;88:718-729.

145. Jiang Z-M, Dai S-P, Xu Y-Q, Li T, Xie J, Li C, and Zhang Z-H: Crizotinib-loaded polymeric nanoparticles in lung cancer chemotherapy. Med Oncol. 2015;32:193.

146. Dreaden EC, Kong YW, Morton SW, Correa S, Choi KY, Shopsowitz KE, Renggli K, Drapkin R, Yaffe MB, and Hammond PT. Tumor-targeted synergistic blockade of MAPK and PI3K from a layer-by-layer nanoparticle. Clin Cancer Res. 2015;21:4410-4419.

147. Yang Q, Moulder KR, Cohen MS, Cai S, and Forrest LM: Cabozantinib loaded DSPE-PEG(2000) micelles as delivery system: Formulation, characterization and cytotoxicity evaluation. BAOJ Pharm Sci. 2015;1:001.

148. Yoo M-K, Park I-K, Lim H-T, Lee S-J, Jiang H-L, Kim Y$\mathrm{K}$, Choi Y-J, Cho M-H, and Cho C-S: Folate-PEGsuperparamagnetic iron oxide nanoparticles for lung cancer imaging. Acta Biomater. 2012;8:3005-3013.

149. Zhou S, Huo D, Hou C, Yang M, Fa H, Xia C, and Chen M: Mesoporous silica-coated quantum dots functionalized with folic acid for lung cancer cell imaging. Anal Methods. 2015;7:9649-9654.

150. He Z, Huang J, Xu Y, Zhang X, Teng Y, Huang C, Wu $\mathrm{Y}$, Zhang $\mathrm{X}$, Zhang $\mathrm{H}$, and Sun $\mathrm{W}$ : Co-delivery of cisplatin and paclitaxel by folic acid conjugated amphiphilic PEG-PLGA copolymer nanoparticles for the treatment of non-small lung cancer. Oncotarget. 2015; 6:42150-42168.

151. Wang F, Wang Y, Ma Q, Cao Y, and Yu B: Development and characterization of folic acid-conjugated chitosan nanoparticles for targeted and controlled delivery of 
gemcitabinein lung cancer therapeutics. Artif Cells Nanomed Biotechnol. 2016:1-9.

152. Muralidharan R, Babu A, Amreddy N, Basalingappa K, Mehta M, Chen A, Zhao YD, Kompella UB, Munshi A, and Ramesh R: Folate receptor-targeted nanoparticle delivery of HuR-RNAi suppresses lung cancer cell proliferation and migration. J Nanobiotechnol. 2016;14:47.

153. Liu K, Dai L, Li C, Liu J, Wang L, and Lei J: Selfassembled targeted nanoparticles based on transferrinmodified eight-arm-polyethylene glycol-dihydroartemisinin conjugate. Sci Rep. 2016;6:29461.

154. Guo Y, Wang L, Lv P, and Zhang P: Transferrinconjugated doxorubicin-loaded lipid-coated nanoparticles for the targeting and therapy of lung cancer. Oncol Lett. 2015;9:1065-1072.

155. Chi L, Na M-H, Jung H-K, Vadevoo SMP, Kim C-W, Padmanaban G, Park T-I, Park J-Y, Hwang I, Park KU, Liang F, Lu M, Park J, Kim I-S, and Lee B-H: Enhanced delivery of liposomes to lung tumor through targeting interleukin-4 receptor on both tumor cells and tumor endothelial cells. J Control Release. 2015;209:327-336.

156. Von Hoff DD, Mita MM, Ramanathan RK, Weiss GJ, Mita AC, LoRusso PM, Burris HA, Hart LL, Low SC, Parsons DM, Zale SE, Summa JM, Youssoufian H, and Sachdev JC: Phase I study of PSMA-targeted docetaxelcontaining nanoparticle BIND-014 in patients with advanced solid tumors. Clin Cancer Res. 2016;22:3157.

157. Chittasupho C, Xie S-X, Baoum A, Yakovleva T, Siahaan TJ, and Berkland CJ: ICAM-1 targeting of doxorubicinloaded PLGA nanoparticles to lung epithelial cells. Eur J Pharm Sci. 2009;37:141-150.

158. Karra N, Nassar T, Laenger F, Benita S, and Borlak J: Safety and proof-of-concept efficacy of inhaled drug loaded nano- and immunonanoparticles in a c-Raf transgenic lung cancer model. Curr Cancer Drug Targets. 2013;13:11-29.
159. Alibolandi M, Ramezani M, Abnous K, Sadeghi F, Atyabi F, Asouri M, Ahmadi AA, and Hadizadeh F: In vitro and in vivo evaluation of therapy targeting epithelial-cell adhesion-molecule aptamers for non-small cell lung cancer. J Control Release. 2015;209:88-100.

160. Li W, Zhao X, Du B, Li X, Liu S, Yang X-Y, Ding H, Yang W, Pan F, Wu X, Qin L, and Pan Y: Gold nanoparticle-mediated targeted delivery of recombinant human endostatin normalizes tumour vasculature and improves cancer therapy. Sci Rep. 2016;6:30619.

161. Yang T, Li X, Liu Y, and Bai S: Cationic nanoparticles effectively delivered VEGF SiRNA in A549 cells. NSTI Nanotech. 2011;3:319-321.

162. Zhang Y, Schwerbrock NMJ, Rogers AB, Kim WY, and Huang L: Codelivery of VEGF siRNA and gemcitabine monophosphate in a single nanoparticle formulation for effective treatment of NSCLC. Mol Ther. 2013;21:1559-1569.

Received on March 14, 2017 in final form, August 2, 2017

Reviewed by Joseph Brain Wolfgang Kreyling

Address correspondence to: Ali Dabbagh, PhD

Wellness Research Cluster

Institute of Research Management and Monitoring

University of Malaya

Kuala Lumpur 50603

Malaysia

E-mail: ali.dabbagh@um.edu.my 